\title{
PPAR control of metabolism and cardiovascular functions
}

David Montaigne, Laura Butruille and Bart Staels ${ }^{\dagger}$

University of Lille, Inserm, CHU Lille, Institut Pasteur de Lille, U1011-EGID, Lille, France. †e-mail: bart.staels@pasteur-lille.fr

\begin{abstract}
Peroxisome proliferator-activated receptor- $\alpha$ (PPAR $\alpha)$, PPAR $\delta$ and PPAR $\gamma$ are transcription factors that regulate gene expression following ligand activation. PPAR $\alpha$ increases cellular fatty acid uptake, esterification and trafficking and regulates lipoprotein metabolism genes. PPAR $\delta$ stimulates lipid and glucose utilization by increasing mitochondrial function and fatty acid desaturation pathways. By contrast, PPAR $\gamma$ promotes fatty acid uptake, triglyceride formation and storage in lipid droplets, thereby improving insulin sensitivity and glucose metabolism. PPARs also exert anti-atherogenic and anti-inflammatory effects on the vascular wall and immune cells. Clinically, PPAR $\gamma$ activation by glitazones and PPAR $\alpha$ activation by fibrates improve insulin resistance and dyslipidaemia, respectively. PPARs are also physiological master switches in the heart, steering cardiac energy metabolism in cardiomyocytes, thereby affecting pathological heart failure and diabetic cardiomyopathy. Novel PPAR agonists in clinical development are providing new opportunities in the management of metabolic and cardiovascular diseases.
\end{abstract}

\section{Introduction}

Cardiovascular diseases (CVD) are a leading cause of morbidity and mortality, representing $33 \%$ of deaths worldwide ${ }^{1}$. Obesity, diabetes mellitus, dyslipidaemia and hypertension are risk factors for CVD and can be targeted by pharmacological strategies. Although LDL-cholesterol lowering with statins reduces the risk of CVD, a residual risk persists ${ }^{2}$, particularly in patients with diabetes and combined dyslipidaemia characterized by high triglyceride and low HDL- 
cholesterol levels. The peroxisome proliferator-activated receptor (PPAR) transcription factors regulate genes that encode proteins controlling metabolic homeostasis and function in multiple organs, including the liver, adipose tissue, intestine, skeletal muscle, vascular wall and heart. PPAR agonists (such as fibrates for PPAR $\alpha$ and glitazones for PPAR $\gamma$ ) have been used for decades in the treatment of dyslipidaemia and diabetes. However, clinical trials of these agents have resulted in mixed results on reducing the risk of CVD.

In this Review, we discuss how PPARs regulate the atherogenic lipid profile, vascular atherosclerosis and cardiac remodelling. Given the abundant literature on their metabolic and vascular functions, we focus on findings published after 2017, whereas the cardiac functions of PPARs are covered in more detail, given the paucity of clinical pharmacological data in this field.

\section{Overview of the PPAR family}

PPAR $\alpha$ (also known as nuclear receptor subfamily 1 group C member 1 (NR1C1)), PPAR $\delta$ (also known as PPAR $\beta$ or NR1C2) and PPAR $\gamma$ (also known as NR1C3) are nuclear receptors regulating numerous metabolic functions through intra-organ and inter-organ connections ${ }^{3}$. The genes encoding PPAR $\alpha, \operatorname{PPAR} \delta$ and PPAR $\gamma$ are located on human chromosomes 22, 6 and 3 and murine chromosomes 15, 17 and 6, respectively. The PPAR proteins are organized into domains. The N-terminal domain exerts activation functions and determines target-gene specificity. The DNA-binding domain contains two zinc-fingers that allow binding to DNA PPAR response elements (PPRE). The hinge region provides structural flexibility and docks several nuclear receptor cofactors. The $\mathrm{C}$-terminal domain contains the ligand-binding domain and is involved in the interaction with its obligatory heterodimer partner, the retinoid X receptor and other co-regulators, such as nuclear receptor corepressor 1 , PPAR $\gamma$-coactivator $1 \alpha$ (PGC1 $\alpha$ ) or receptor-interacting protein $140^{4,5}$. PPARs also extensively crosstalk with other 
regulatory factors, such as the Krüppel-like factors (KLFs), which modulate PPAR $\gamma$-mediated adipogenesis $^{6-8}$, PPAR $\alpha$ expression in cardiomyocytes ${ }^{9,10}$ and PPAR $\delta$ activity in skeletal muscle $^{11}$. PPAR activity is also modulated by environmental factors, such as nutritional status and circadian timing, through multiple interactions and post-translational modifications ${ }^{12}$.

PPARs are lipid sensors that modulate whole-body energy metabolism. PPAR $\alpha$ promotes the adaptive response to fasting by controlling fatty acid transport, oxidation and ketogenesis. PPAR $\gamma$ is a master regulator of adipogenesis, which can increase lipid storage, improve insulin sensitivity and glucose metabolism through a lipid-steal action. PPAR $\delta$ increases both lipid and glucose metabolism and participates in the response to exercise by regulating the switch from glycolytic to oxidative muscle fibres ${ }^{3}$.

Ligand-activated PPARs bind to PPREs, consisting of a repetition of the AGG(A/T)CA sequence spaced by one or two nucleotides (direct repeat 1 or direct repeat 2) in the regulatory regions of target genes, a process called transactivation ${ }^{5}$. PPARs also exert anti-inflammatory effects by repressing pro-inflammatory pathways, a process termed transrepression ${ }^{5,13}$. However, the mechanisms mediating transrepression are not understood in detail.

Unsaturated fatty acid and derivatives provided by the diet, de novo lipogenesis and triglyceride lipolysis are natural PPAR ligands (Table 1). Synthetic PPAR agonists were serendipitously identified and comprise the fibrates and glitazones, which activate PPAR $\alpha$ and PPAR $\gamma$, respectively. The discovery of the PPAR isotypes allowed targeted screening for agonists with single, dual or pan-PPAR agonist profiles. Examples include the PPAR $\alpha$ agonist pemafibrate $^{14}$, PPAR $\delta$ agonist seladelpar ${ }^{15}$, the dual PPAR $\alpha$ and PPAR $\gamma$ agonist saroglitazar ${ }^{16}$, the dual PPAR $\alpha$ and PPAR $\delta$ agonist elafibranor ${ }^{17}$, and the pan-PPAR agonists lanifibranor ${ }^{18}$ and chiglitazar ${ }^{19}$, some of which are in development for the treatment of metabolic diseases and $\mathrm{CVD}^{3,12}$. Given that compounds with different chemical structures display distinct receptor-binding modalities, inducing specific conformational changes and cofactor 
interactions, different regulatory responses might occur. Together with compound-specific pharmacokinetic characteristics, this situation results in selective PPAR modulator profiles, which might improve clinical efficacy (Table 1).

\section{Metabolic control by PPARs}

\section{Liver}

PPAR $\alpha$ is the predominant PPAR isoform in the liver, where it regulates genes encoding proteins involved in lipid and lipoprotein metabolism. Activated by fatty acid released from triglyceride lipolysis, PPAR $\alpha$ increases fatty acid uptake, lipogenesis, oxidation ${ }^{3,12}$ and ketogenesis ${ }^{20}$ depending on the nutritional status (that is, fed or fasted). In the post-prandial state, characterized by high circulating glucose and insulin levels, insulin-activated MAPK and glucose-activated protein kinase $\mathrm{C}$ induce PPAR $\alpha$ activity, thereby favouring fatty acid synthesis, elongation and desaturation, simultaneously producing endogenous PPAR ligands. During prolonged fasting, glucagon-activated protein kinase A and induction of the AMPK pathway increase PPAR $\alpha$ signalling through phosphorylation and interaction with the PGC1 $\alpha$ coactivator $^{5}$, consequently switching fatty acid metabolism to oxidation and ketogenesis ${ }^{5,12}$. Therefore, fatty acid synthesis and oxidation display a circadian rhythmicity aligned with a circadian regulation of hepatic PPAR $\alpha$. Accordingly, lipid-lowering treatment with a PPAR $\alpha$ agonist is more efficacious at the peak of liver PPAR $\alpha$ expression $^{21}$. PPAR $\alpha$ also contributes to the adaptation in energy substrate utilization by increasing ketone body production during pathophysiological conditions such as sepsis and functioning with PPAR $\gamma$ to prevent sepsisrelated cardiac dysfunction, thereby improving survival ${ }^{22,23}$.

Well-known regulatory stimuli of PPAR $\alpha$ expression are fasting, growth hormones, leptin and glucocorticoids ${ }^{13}$. Induction of hepatocyte PPAR $\alpha$ expression upon fasting occurs through a complex autoregulatory loop that involves lysine-specific demethylase 6B (KDM6B), NAD-dependent protein deacetylase sirtuin 1 (SIRT1) and PPAR $\alpha$. Interference 
with this complex by hepatocyte-specific $K d m 6 b$ deletion in mice lowers the expression of PPAR $\alpha$ and its target genes ${ }^{24}$. Moreover, mice with hepatocyte-specific Vps 15 deletion (the gene encoding regulatory subunit 4 of phosphoinositide 3-kinase, a protein involved in autophagy) have a loss of autophagy, leading to the accumulation of the two PPAR $\alpha$ corepressors, histone deacetylase 3 and nuclear receptor corepressor 1 (NCOR1), thereby repressing PPAR $\alpha$ transcription $^{25}$. In addition, hepatic PPAR $\alpha$ polyubiquitination and degradation are inhibited in fasted mice with hepatic Paqr3 deletion ${ }^{26}$.

Obesity, diabetes and non-alcoholic fatty liver disease (NAFLD) increase the risk of $\mathrm{CVD}^{27}$. Visceral obesity and hepatic steatosis drive atherogenic dyslipidaemia, which is characterized by plasma hypertriglyceridaemia, increased concentrations of small dense LDL particles and decreased HDL-cholesterol levels, thereby increasing the risk of myocardial infarction, stroke or revascularization (Table 2). Hepatic PPARA mRNA levels and activity decrease with the progression of NAFLD, owing to elevated levels of G protein pathway suppressor 2, a subunit of the PPAR-NCOR1 complex, in non-alcoholic steatohepatitis (NASH) and liver fibrosis ${ }^{28,29}$. Hepatic PPAR $\alpha$-deficient mice have increased liver steatosis and inflammation, with increased levels of pro-inflammatory macrophages, hyperlipidaemia and hypercholesterolemia with ageing ${ }^{30-32}$. Impaired hepatic PPAR $\alpha$ metabolism results in compensatory extrahepatic fatty acid oxidation (FAO), protecting against fasting-induced hepatosteatosis in mice ${ }^{33}$. Fibroblast growth factor 21 is a fasting-induced PPAR $\alpha$ target with lipid-lowering ${ }^{34}$ and hepato-protective properties and is currently under development for the treatment of $\mathrm{NASH}^{35,36}$.

In patients with dyslipidaemia, fibrates lower plasma triglyceride levels and increase plasma levels of HDL cholesterol, apolipoprotein A-I (ApoA-I) and ApoA-II ${ }^{13}$. PPAR $\alpha$ increases intravascular lipolysis by inducing PPRE-mediated expression and activity of the enzyme lipoprotein lipase (which hydrolyses triglycerides in lipoproteins) and expression of 
its activator ApoA-V, while decreasing expression of its inhibitor ApoC-III ${ }^{12}$ (Table 2). In mice, pemafibrate corrects dyslipidaemia by increasing reverse cholesterol transport and decreasing levels of systemic and hepatic inflammatory markers, thereby decreasing histological NASH and atherosclerosis ${ }^{14,37,38}$.

PPAR $\alpha$ activation also affects the levels of liver and plasma bioactive lipids. In patients with dyslipidaemia, fenofibrate decreases plasma levels of atypical deoxysphingolipids ${ }^{39}$. In non-obese diabetic mice, fenofibrate increases very-long-chain sphingolipids and exerts antiinflammatory and anti-apoptotic actions in the endocrine pancreas ${ }^{40}$. Conversely, PPAR $\alpha$ activation in humans with diabetes does not improve glucose metabolism ${ }^{41,42}$. Interestingly, in mice, NASH-induced myocardial steatosis, inflammation and fibrosis are prevented by PPAR $\alpha$ $\operatorname{activation}^{43}$.

Hepatic PPAR $\delta$ induces FAO, increases lipogenesis (to supply fatty acids as skeletal muscle energy substrates), increases glucose uptake, glycogen storage and glycolysis, and decreases gluconeogenesis ${ }^{3,12}$. The differential functions of hepatic PPAR $\alpha$ and PPAR $\delta$ are not well understood. PPAR $\alpha$ and PPAR $\delta$ have similar effects on plasma lipoprotein metabolism (raising plasma HDL-cholesterol levels and lowering LDL-cholesterol and triglyceride levels), but can also lower levels of free fatty acids. PPAR $\delta$ also lowers ApoC-III levels and increases ApoA-II levels ${ }^{12}$ (Table 2). Moreover, PPAR $\delta$ stimulates the expression of hepatic PPAR $\alpha$ and its target genes ${ }^{44}$. Interestingly, PPAR $\delta$ expression is reduced in the livers of patients with severe hepatic steatosis ${ }^{45}$, but do not decrease further as the disease progresses to $\mathrm{NASH}^{28}$. PPAR $\delta$-mediated inhibition of VLDL receptor expression might protect against steatosis ${ }^{45}$.

In mice, hepatocyte PPAR $\gamma$ activation induces steatosis ${ }^{46}$, an effect not observed in humans ${ }^{12,28}$. However, PPAR $\gamma$ is expressed in rodent and human hepatic stellate cells, and PPAR $\gamma$ activation protects against hepatic stellate cells conversion to profibrogenic myofibroblasts ${ }^{47}$. 


\section{Adipose tissue}

Adipose tissue is composed of adipocytes and immune, endothelial and vascular cells. Adipose tissue is a secretory organ, which affects liver, vessel and heart function, secreting adipokines, microparticles and lipids. Body distribution, quality and level of expansion regulate the biological activity of adipose tissue.

In contrast to subcutaneous white adipose tissue, the amount of visceral white adipose tissue positively correlates with the risk of $\mathrm{CVD}^{48}$, whereas brown and beige adipose tissue protects the cardiovascular system by promoting energy expenditure ${ }^{48}$. Remote adipose tissue depots exert endocrine cardiovascular regulatory actions by secreting bioactive substances, whereas epicardial and perivascular adipose tissue modulates cardiovascular functions through paracrine effects ${ }^{48,49}$. In obesity, diabetes or inflammation, the adipose secretome becomes proinflammatory and pro-atherogenic, thereby increasing the risk of $\mathrm{CVD}^{48}$.

- White adipose tissue. PPAR $\gamma$ increases adipocyte differentiation, fatty acid uptake and storage into lipid droplets, thereby decreasing ectopic lipid deposition and improving systemic insulin sensitivity ${ }^{3,12}$ (Table 2). Studies have shed further light on the molecular mechanisms that regulate PPAR $\gamma$ activity in adipose tissue. Deficiency of the mediator of RNA polymerase II transcription subunit 19 (MED19) in mouse adipocytes reduces PPAR $\gamma$-induced adipogenesis ${ }^{50}$. Adipocyte-specific deletion of transcriptional coactivator with PDZ-binding motif improved glucose tolerance and insulin sensitivity and decreased adipose tissue inflammation by de-repressing PPAR $\gamma$ activity in mice ${ }^{51}$. PPAR $\gamma$ also interacts with the epigenetic modulator methylcytosine dioxygenase TET1 to control adipocyte DNA methylation, target-gene transcription and insulin sensitivity in vitro in 3T3-L1 adipocytes ${ }^{52,53}$. Moreover, heat shock protein 20 interacts with the ubiquitin ligase complex F-box only protein 
4 to promote PPAR $\gamma$ degradation, and its deletion in mice mimicked PPAR $\gamma$ activation $^{54}$. Adipose tissue-specific PPAR $\gamma_{2}$ deficiency results in metabolic inflexibility in mice ${ }^{55}$ (Table 3), reduces adipose tissue lipid storage and redirects lipids to muscle, causing triglyceride accumulation in skeletal muscle and increased insulin resistance ${ }^{55}$. Interestingly, a genetic mutation that prevents PPAR $\gamma$ SUMOylation of Lys 107 improves insulin sensitivity in mice with diet-induced obesity without increasing adiposity ${ }^{56}$.

PPAR $\delta$ modulates preadipocyte differentiation in vitro ${ }^{57}$. Moreover, PPAR $\delta$ drives the polarization of anti-inflammatory M2 macrophages in adipose tissue and exerts antiinflammatory properties ${ }^{58}$. In mice, constitutive $\operatorname{PPAR} \delta$ activation in adipose tissue induce weight loss and protect against obesity ${ }^{59,60}$. However, this effect is not observed in individuals who are overweight, although an improved lipid profile and reduced waist circumference were observed $^{61}$.

- Brown adipose tissue and browning. In brown adipose tissue, PPAR $\gamma$ induces the expression of thermogenic and mitochondrial biogenesis proteins, including uncoupling protein 1, PR domain-containing zinc finger protein 16 (PRDM16) and PGC1 $\alpha^{3}$. In addition, PPAR $\gamma$ can regulate brown adipocyte differentiation. Glitazone treatment activates white adipose tissue browning and increases expression of uncoupling protein 1 and cell death-inducing DNA fragmentation factor- $\alpha$ subunit-like effector A and SIRT1. In conditions of energy deficiency, SIRT1 is activated and deacetylates PPAR $\gamma$ on Lys268 and Lys293, which leads to the recruitment of PRDM16 and expression of brown adipose tissue genes ${ }^{62}$. Regulation of PPAR $\gamma$ through this pathway or by inhibition of Ser273 phosphorylation, which protects mice from insulin resistance induced by a high-fat $\operatorname{diet}^{63}$, could be applied in the design of novel PPAR $\gamma$ agonists to dissociate insulin-sensitizing from the adverse effects of glitazone treatment (adiposity, reduced bone density, fluid retention and cardiac hypertrophy) ${ }^{64}$. 
PPAR $\alpha$ is highly expressed in brown adipose tissue, where it regulates the expression of lipid oxidation and thermogenesis genes through interaction with $\mathrm{PGC} 1 \alpha^{65}$ following activation by ligands released by $\beta$-adrenergic stimulation of lipolysis. Although PPAR $\alpha$ expression is low in white adipose tissue ${ }^{3}$, activation of PPAR $\alpha$ by adipose triglyceride ligasemediated lipolysis-derived fatty acid ligands promotes mitochondrial activity, adipose tissue energy metabolism and a brown-beige adipose tissue-like phenotype ${ }^{66-68}$. PPAR $\alpha$ agonist treatment reduces adiposity in male but not in female mice, probably owing to negative interference between PPAR $\alpha$ and oestrogen receptor signalling leading to sex-specific regulatory responses of FAO genes in the liver ${ }^{69}$. In addition, the interaction between PPAR $\delta$ and PGC1 $\alpha$ also activates FAO and thermogenesis in mice $^{3}$ (Table 2).

- Perivascular adipose tissue. Perivascular adipose tissue has an important function in atherogenesis. Pparg deletion inhibited the development of brown-like perivascular adipose tissue, which resulted in larger atherosclerotic lesions with increased macrophage infiltration and increased local concentrations of IL-1 $\beta$, IL- 6 and tumour necrosis factor ${ }^{70}$.

\section{Intestine}

The intestine provides the organism with energy through nutrient absorption and is also an active secretory organ, producing incretins, such as glucagon-like peptide 1 (GLP1), which, after binding to the GLP1 receptor, improves glucose homeostasis and can reduce the risk of CVD in patients with diabetes ${ }^{71,72}$. In the gut, the microbiota acts as an 'endocrine-like organ' producing bioactive metabolites affecting host homeostasis, such as short-chain fatty acids, secondary bile acids and trimethylamine (which is further oxidized to trimethylamine $\mathrm{N}$-oxide in the liver). Gut microbiota dysbiosis affects the gut barrier, resulting in subclinical sepsis and 
systemic inflammation, promoting metabolic conditions and CVDs, such as obesity, diabetes, atherosclerosis and heart failure 27,73 (Table 2).

Short-chain fatty acids produced by the gut microbiota protect against obesity and improve insulin sensitivity through the downregulation of adipose tissue and liver PPAR $\gamma$ expression, thereby favouring oxidative metabolism and reducing hepatic steatosis and lipogenesis ${ }^{74}$. Butyrate regulates metabolism by activating colonocyte PPAR $\gamma^{75}$, thereby lowering the synthesis of inducible nitric oxide synthase, preserving epithelial hypoxia, preventing dysbiosis and improving mucosal defences in mice fed a high-fat diet ${ }^{76,77}$.

Caloric restriction also induces duodenal PPAR $\alpha$ expression ${ }^{78}$. Intestinal PPAR $\alpha$ activation increases intestinal epithelial cell FAO and HDL production and reduces chylomicron secretion by enterocytes, thereby controlling postprandial hyperlipidaemia ${ }^{12,79,80}$.

The improved glucose tolerance with PPAR $\delta$ activation is partly due to its stimulatory effect on GLP1 release from enteroendocrine L cells ${ }^{81}$. Moreover, enterocyte deficiency of $\operatorname{PPAR} \delta$ prevents the PPAR $\delta$-agonist-inducted increase in plasma HDL-cholesterol levels ${ }^{60}$. Therefore, intestinal PPAR $\delta$ protects against obesity, insulin resistance and dyslipidaemia ${ }^{60}$ (Table 2).

\section{Skeletal muscle}

Physical exercise exerts beneficial effects on several risk factors for CVD, improving glucose and lipid metabolism and control of body weight. Exercise training promotes endurance by increasing skeletal muscle oxidative metabolism and delaying the depletion of carbohydrates stored as glycogen in the liver and muscle. PPAR $\delta$ is highly expressed in skeletal muscle, where it induces a switch from glycolytic to oxidative muscle fibres. PPAR $\delta$ overexpression in mouse skeletal muscle generates a 'marathon-like' phenotype ${ }^{82,83}$. PPAR $\delta$ overexpression in vivo in rodent skeletal muscle promotes FAO and increases mitochondrial biogenesis by 
protecting PGC1 $\alpha$ from degradation and inducing nuclear respiratory factor 1 (NRF1) expression $^{84}$. In cooperation with AMPK, PPAR $\delta$ overexpression in vivo in rodent skeletal muscle and in vitro in $\mathrm{C} 2 \mathrm{C} 12$ muscle cells increases glucose transporter type 4 (GLUT4) expression during exercise training via NRF1-MEF2A ${ }^{85}$. PPAR $\delta$ agonist treatment also decreases visceral adipose tissue and skeletal muscle inflammation by increasing antiinflammatory regulatory $\mathrm{T}$ cell numbers in lymph nodes of diet-induced obese mice ${ }^{86}$. Finally, by preserving systemic glucose levels, PPAR $\delta$ activation with GW501516 in mice delays the onset of hypoglycaemia during exercise, resulting in increased running endurance ${ }^{87}$ (Table 2).

PPAR $\alpha$ overexpression in mouse skeletal muscle also increases FAO, but reduces insulin-stimulated glucose uptake owing to GLUT4 repression, resulting in glucose intolerance despite being protected from obesity ${ }^{88}$. PPAR $\alpha$ agonists reverse palmitate-induced insulin resistance in myotubes by increasing FAO and limiting ceramide accumulation in vitro ${ }^{89}$. PPAR $\gamma$ improves skeletal muscle insulin sensitivity via the lipid-steal action to increase fatty acid storage in white adipose tissue lipid droplets ${ }^{12}$.

\section{PPARs in atherosclerosis}

\section{Vascular function and inflammation}

Atherosclerosis is characterized by endothelial dysfunction leading to immune cell infiltration, cholesterol deposition and further atherosclerotic plaque development containing a necrotic core and regions of calcification ${ }^{90}$. Risk factors for atherosclerosis include dyslipidaemia, hypertension, obesity and smoking, which increase vascular permeability, inflammation and oxidative stress $^{91}$. In the early 2000s, PPARs were shown to reduce endothelial cell activation and adhesion and vascular smooth muscle cell and trans-endothelial leukocyte migration ${ }^{92}$. PPARs exert anti-inflammatory and antioxidant effects in cells of the vascular wall and reduce 
macrophage foam cell formation by inducing reverse cholesterol transport, thereby promoting plaque stability $^{92}$ (Table 2).

Data have shown that endothelial PPAR $\gamma$ deficiency also accelerates age-induced vascular dysfunction, inflammation and senescence via mechanisms involving increased NADPH oxidase and Rho-associated protein kinase activity ${ }^{93}$. In human primary endothelial cells, PPAR $\gamma$ promotes DNA repair by interacting with the E3 ubiquitin-protein ligase UBR5 and the DNA-damage sensor MRN complex-interacting protein, promoting serine-protein kinase ATM-mediated signalling, a pathway that is disrupted in patients with pulmonary arterial hypertension ${ }^{94}$. In mouse endothelial cells, the LDL-receptor-related protein 1 (LRP1) controls lipid, glucose and energy metabolism, functioning as a PPAR $\gamma$ coactivator to regulate the expression of PPAR $\gamma$ and its target genes ${ }^{95}$. These surprising findings identify a role for the endothelial LRP1-PPAR $\gamma$ complex in vascular function and systemic energy metabolism ${ }^{95}$. $\operatorname{PPAR} \gamma$ mediates bone morphogenetic protein 2 inhibition of vascular smooth muscle cell proliferation by transforming growth factor- $\beta 1$ (TGF $\beta 1$ )-induced interference through the STAT3-FOXO1 and TGF $\beta 1-S M A D 3 / 4$ pathways and by regulating the glycolytic enzymes phosphofructokinase (PFK) and protein phosphatase 1 regulatory subunit $3 \mathrm{G}^{96}$. The methylation status of the Pparg promoter region is regulated by DNA (cytosine-5)methyltransferase 1 (DNMT1) in murine macrophages ${ }^{97}$. Increased DNMT1 levels in transgenic mouse macrophages resulted in decreased PPAR $\gamma$ expression and increased proinflammatory cytokine production, leading to aggravation of atherosclerosis in mice ${ }^{97}$. PPAR $\gamma$ activation counteracted the pro-inflammatory profile promoted by DNMT1 overexpression in macrophages ${ }^{97}$. Finally, PPAR $\gamma$ induces anti-inflammatory M2 macrophage polarization by facilitating intracellular glutamine metabolism ${ }^{98,99}$.

The anti-inflammatory actions of PPAR $\alpha$ have also been extensively discussed ${ }^{92}$. Interestingly, circulating monocyte numbers decrease with short-term fasting in humans, 
through a mechanism involving AMPK-PPAR $\alpha$ suppression of systemic CC-chemokine ligand 2 production that reduces bone marrow monocyte mobilization, as observed in fasted wild-type but not PPAR $\alpha$-deficient mice ${ }^{100}$. As a consequence, chronic inflammatory diseases are improved through dietary intervention ${ }^{100}$.

PPAR $\delta$ reduces atherosclerotic lesion progression through increasing plasma levels of HDL and exerting anti-inflammatory activity within the vessel wall in $A p o e^{-/-}$mice ${ }^{101}$. Another study showed that PPAR $\delta$ increases endothelial relaxation in diabetic mice ${ }^{102}$ and prevents accumulation of reactive oxygen species by increasing mitochondrial uncoupling protein 2 expression in mouse aortic endothelial cells ${ }^{103}$. PPAR $\delta$ also induces microRNA-100, leading to VLDL-receptor inhibition in endothelial cells in vitro ${ }^{104}$ and inhibition of vascular smooth muscle cell proliferation through SIRT1 activation ${ }^{105}$.

\section{Regulation of ischaemic events}

Several studies on animal models of ischaemia-reperfusion injury that mimicked an acute myocardial infarction demonstrated cardioprotective effects, with reduced infarct size after PPAR $\gamma^{106}, \operatorname{PPAR} \alpha^{107}$ or PPAR $\delta^{108}$ activation in rodent hearts. The underlying mechanisms mediating this cardioprotection probably involve decreased oxidative stress, apoptosis ${ }^{109}$ and inflammation ${ }^{107}$. Interestingly, treatment with the PPAR $\gamma$ agonist rosiglitazone decreased ischaemia-reperfusion injury in diabetic mice ${ }^{110}$ and in non-diabetic mice ${ }^{111}$, indicating a mechanism of action that is independent of glucose control.

\section{PPAR agonists in CVD clinical studies}

Overall, PPARs exert favourable anti-inflammatory and anti-atherogenic effects in atherosclerosis, which can lower the risk of CVD. Moreover, glitazones prevent the progression to diabetes in Hispanic women with prior gestational diabetes ${ }^{112}$. In the secondary prevention 
PROactive trial ${ }^{113}$ in patients with type 2 diabetes, pioglitazone significantly decreased the secondary end point of all-cause mortality, non-fatal myocardial infarction and stroke. However, the primary end point was not achieved owing to an increase in peripheral revascularization ${ }^{113}$. In the IRIS study ${ }^{114}$, pioglitazone administered to insulin-resistant individuals after ischaemic stroke or transient ischaemic attack reduced the risk of stroke and myocardial infarction. Unfortunately, glitazone treatment increases the risk of bone fractures, weight gain and oedema, which might precipitate heart failure. Although tesaglitazar induces cardiac mitochondrial dysfunction in mice by inhibiting the SIRT1-PGC1 $\alpha$ pathway ${ }^{115}$, no data have reported direct deleterious effects of glitazones on heart function. Studies on cardiomyocyte-specific PPAR $\gamma$-deficient mice revealed that the effects of glitazones on cardiac dysfunction primarily occur through extracardiac actions, such as via the induction of peripheral oedema ${ }^{116-118}$. Therefore, the development of oedema should be monitored during glitazone treatment, especially in patients at risk of heart failure.

Whereas both the FIELD ${ }^{41}$ and ACCORD ${ }^{42}$ clinical trials did not achieve statistically significant reductions in cardiovascular events in patients with type 2 diabetes treated with fenofibrate, subgroups analysis suggested that fibrates might benefit patients with high plasma triglyceride $(\geq 200 \mathrm{mg} / \mathrm{dl})$ and low plasma HDL-cholesterol levels $\mathrm{s}^{41,42}$. This hypothesis is now being tested in the PROMINENT trial ${ }^{119}$, which is enrolling 10,000 patients with type 2 diabetes, mild-to-moderate hypertriglyceridaemia (200-499 mg/dl) and low plasma HDLcholesterol levels $(\leq 40 \mathrm{mg} / \mathrm{dl})$, who will be randomly assigned to pemafibrate treatment ( $0.2 \mathrm{mg}$ twice daily) or placebo. The primary end point is a composite of non-fatal myocardial infarction, ischaemic stroke, hospitalization for angina that requires urgent coronary revascularization and cardiovascular death (results expected in 2022) ${ }^{120}$. Previous phase II and phase III trials revealed that pemafibrate treatment in patients with type 2 diabetes improves lipid profiles and decreases risk factors for CVD. Pemafibrate therapy is more efficient in 
lowering plasma triglyceride levels and does not increase alanine aminotransferase nor $\gamma$ glutamyltransferase levels compared with fenofibrate therapy ${ }^{121,122}$. This novel, selective PPAR $\alpha$ modulator seems promising in lowering the risk of CVD in patients with diabetes and dyslipidaemia.

\section{PPARs in healthy hearts}

\section{Physiology}

The heart utilizes different carbon substrates to produce energy. Although the adult heart primarily consumes fatty acids, it shows fuel flexibility and can metabolize glucose, lactate, fatty acid and ketone bodies (Box 1). Nutrients are used by the heart to maintain muscle activity and for anabolic reactions, such as physiological cardiac growth (cardiomyocyte multiplication) in the fetus and pathological cardiac remodelling (cardiomyocyte hypertrophy). Cardiac metabolism is flexible and can switch to preferred nutrients by the action of upstream regulators. PPARs are master switches, which fine tune the cardiomyocyte enzymatic machinery ${ }^{123,124}$ (Box 1; Figs 1,2).

During development, the changing environment induces alterations in cardiac metabolism via upstream master switches (Box 1). The fetal metabolic phenotype is characterized by high hypoxia-inducible factor (HIF) and low PPAR $\alpha-P G C 1 \alpha$ activity ${ }^{125}$, which results in high expression of glycolytic genes and low expression of genes associated with fatty acid catabolism and mitochondrial energy production. This fetal metabolic phenotype of cardiomyocytes provides high quantities of glycolytic intermediates, necessary for nucleotide, amino-acid and lipid biosynthesis ${ }^{126}$, thereby promoting cardiomyocyte multiplication by supporting growth and anabolism ${ }^{127}$. Cardiomyocyte depletion of the mitochondrial pyruvate carrier induces early hypertrophy and maladaptation to myocardial stress $^{128,129}$, with increased glycolysis in the heart, suggesting a crucial role of the pyruvate- 
lactate axis in cardiomyocyte biosynthesis and potentially cell proliferation ${ }^{128}$. Moreover, low mitochondrial FAO protects against DNA damage induced by reactive oxygen species and subsequent cell cycle arrest ${ }^{130}$.

Although a direct role of PPARs in this physiological metabolic switch has not yet been proven, PPARs are thought to be involved in this switch. Indeed, a switch in the HIF and PPAR $\alpha-$ PGC1 $\alpha$ signalling balance occurs within a few days after birth in the neonatal heart into an 'adult phenotype', which relies on fatty acid catabolism and strong mitochondrial oxidative phosphorylation ${ }^{131,132}$ (Box 1). It is tempting to speculate that PPAR $\alpha$ or PPAR $\delta$ activation might also reduce pathological cardiac hypertrophy through their stimulatory actions on FAO (see below).

\section{Adult hearts}

All PPARs are found in the adult heart, with varying levels of expression: PPAR $\alpha$ and PPAR $\delta$ are highly expressed in the heart at levels similar to those in other metabolically active tissues, such as the liver and skeletal muscle ${ }^{123}$. PPAR $\gamma$ is expressed at very low levels in the adult heart, particularly compared with levels in adipose tissue (cardiac levels of PPAR $\gamma$ are approximately $2 \%$ of those in adipose tissue) $)^{133}$.

Studies using mice with genetic deletion or overexpression of PPARs (mostly in cardiomyocytes) have shown differential roles for these proteins in the regulation of the 'normal' adult metabolic phenotype, that is, the production of large amounts of ATP via mitochondrial FAO. Although a cardiomyocyte-specific Ppara-deletion model has not yet been generated, hearts from ubiquitously PPAR $\alpha$-deficient mice have low expression levels of genes encoding proteins involved in sarcolemmal transport (fatty acid translocase (FAT; also known as CD36) and fatty acid transport protein 1 (FATP1)), mitochondrial transport (carnitine O-palmitoyltransferase 1 (CPT1) and malonyl-CoA decarboxylase (MCD)), and mitochondrial 
(long-chain specific acyl-CoA dehydrogenase (LCAD), medium-chain specific acyl-CoA dehydrogenase (MCAD) and short-chain specific acyl-CoA dehydrogenase) and peroxisomal (acyl-CoA oxidase) oxidation of fatty $\operatorname{acids}^{134,135}$ (Fig. 2). These alterations, which are insensitive to long-term fasting ${ }^{136}$, translate to a switch from fatty acid to glucose and lactate oxidation to maintain sufficient baseline ATP production and cardiac function ${ }^{137}$. However, the metabolic reserve in the hearts of these mice is lower and insufficient to maintain cardiomyocyte levels of high-energy phosphate under high workloads ${ }^{137}$. In addition, deficiency of adipose triglyceride lipase, the enzyme catalysing the first step of triglyceride lipolysis that generates endogenous PPAR $\alpha$ and PPAR $\delta$ ligands, resulted in disrupted mitochondrial oxidation, excessive lipid accumulation, cardiac insufficiency and lethal cardiomyopathy ${ }^{138}$.

Cardiac-restricted PPAR $\alpha$ overexpression results in increased expression levels of genes encoding proteins involved in fatty acid uptake transport and mitochondrial oxidation, at baseline and after short-term fasting in mice ${ }^{139}$. This increased gene expression translated into high myocardial FAO rates and low glucose uptake and oxidation. Moreover, PPAR $\alpha$ overexpression induced myocardial expression of glycerol-3-phosphate acyltransferase (GPAT)) and diacylglycerol acyltransferase, two enzymes involved in the esterification of fatty acids to triglycerides, and adipophilin (also known as perilipin 2), a lipid droplet fatty acidbinding protein ${ }^{139}$ (Fig. 2). Cardiomyocyte lipid droplets accumulated excessively after $24 \mathrm{~h}$ fasting in mice ${ }^{139}$, indicating an imbalance between the increased fatty acid uptake and mitochondrial oxidative capacity. At 2-4 months of age, hearts from PPAR $\alpha$-overexpressing mice developed ventricular hypertrophy (with elevated hypertrophic gene marker expression), left ventricular dilatation and systolic ventricular dysfunction.

Using cardiac-specific Ppara-overexpressing or Ppard-overexpressing transgenic mice, Burkart and colleagues studied the distinct metabolic programmes governed by these 
PPARs ${ }^{140}$. Although both PPARs activate the expression of genes encoding proteins involved in mitochondrial fatty acid transport (CPT1), mitochondrial oxidation (MCAD, LCAD, very long-chain specific acyl-CoA dehydrogenase (VLCAD) and acyl-CoA thioesterase 1) and peroxisomal oxidation (acyl-CoA oxidase), the expression of genes encoding proteins involved in cellular fatty acid transport and activation (FATP1, CD36 and acyl-CoA synthetase 1) and lipogenesis (GPAT and fatty acid synthase) were activated only by PPAR $\alpha$. Genes encoding proteins involved in glucose transport (GLUT4) and glycolysis (PFK and hexokinase) were induced by PPAR $\delta$, but unchanged or decreased by PPAR $\alpha^{140}$ (Fig. 2). In parallel to these distinct metabolic regulatory programmes, diet-induced myocardial triglyceride accumulation occurred in myosin heavy chain (MHC)-PPAR $\alpha$ mice that have cardiac-specific expression of PPAR $\alpha^{140}$. By contrast, MHC-PPAR $\delta$ mice did not have diet-induced myocardial triglyceride accumulation. Cardiomyopathy developed in 2-month-old, cardiac-specific Ppara-transgenic mice receiving either a chow or a high-fat diet. However, MHC-PPAR $\delta$ mice did not develop cardiac hypertrophy or dysfunction even after mice were subjected to a high-fat $\operatorname{diet}^{140}$.

Liu and colleagues developed a tamoxifen-inducible transgenic mouse model to allow cardiomyocyte-specific PPAR $\delta$ induction in adult mice ${ }^{141}$. In addition to an increased expression of genes encoding proteins involved in fatty acid and glucose metabolism, the expression of genes encoding proteins involved in mitogenesis, oxidative phosphorylation and scavenging of reactive oxygen species were also increased after short-term induction of cardiomyocyte-specific PPAR $\delta$ expression ${ }^{141}$. This increased expression translated into increased myocardial oxidative catabolism of both fatty acid and glucose, decreased glycogen content and AMPK activity and increased cardiac performance in an isolated working heart mode $^{141}$. Cardiomyocyte-specific PPAR $\delta$ deletion resulted in the downregulation of genes encoding proteins involved in mitochondrial fatty acid transport (CPT1 and MCD) and oxidation (VLCAD and LCAD), peroxisomal oxidation (acyl-CoA oxidase) and pyruvate 
dehydrogenase kinase $4^{142}$. These hearts had reduced basal myocardial FAO and ATP starvation, demonstrated by increased AMPK activity, despite elevated glucose uptake. These mice had progressive myocardial lipid droplet accumulation, followed by cardiac hypertrophy and dysfunction, which resulted in increased lethality caused by heart failure.

Cardiomyocyte-specific PPAR $\gamma$ deficiency in mice leads to cardiac hypertrophy with preserved systolic function owing to oxidative stress associated with mitochondrial damage ${ }^{116,143}$. Whereas cardiac-specific Pparg-overexpressing transgenic mice have increased expression of GLUT1 and GLUT4 and genes encoding proteins involved in lipid uptake, synthesis and storage ${ }^{133}$ (Fig. 2). This overexpression translated into increased cardiac uptake of both lipids and glucose and storage of fatty acid, triglyceride and glycogen within cardiomyocytes. Consequently, cardiac hypertrophy, dilatation and dysfunction developed within a few months of life ${ }^{133}$. Intriguingly, cardiomyocyte-specific PPAR $\gamma$ overexpression in PPAR $\alpha$-deficient mice increased fatty acid uptake and lipid droplet size, but heart function was preserved $^{144}$. In vitro studies showed that PPAR $\gamma$, while increasing neutral lipid accumulation, reduces endoplasmic reticulum stress ${ }^{145}$. These results suggest that partitioning of lipids to storage and oxidation is cardioprotective.

Altogether, PPAR $\alpha$ and PPAR $\delta$ signalling is activated in adult hearts and drives a normal metabolic phenotype to maintain high-energy phosphate content through mitochondrial oxidation of both fatty acid and glucose. PPAR $\alpha$ signalling activates the cellular fatty acid transport, lipogenesis, mitochondrial and peroxisomal oxidation pathways. By contrast, PPAR $\delta$ signalling activates both cellular fatty acid and glucose transport, mitochondrial oxidation, mitochondrial biogenesis and reactive oxygen species-scavenging systems. The physiological role of PPAR $\gamma$ is probably related to specific intracellular lipid trafficking, determining the balance of lipid signalling species with cardiotoxic potential and the storage of energyproviding triglycerides in droplets in adult cardiomyocytes. 


\section{PPARs in diseased hearts}

\section{Reversal to the fetal metabolic phenotype in heart failure}

Heart failure is a condition of cardiac contractile dysfunction, reducing the ability of the heart to supply sufficient blood to the tissues. The failing heart cannot maintain normal cardiac output and arterial blood pressure without an increase in the cardiac preload, in the first stage of heart failure only during exercise and in end-stage heart disease even at rest (Fig. 1). Two major adaptations that have a large effect on cardiac energy metabolism occur during heart failure $^{146}$. First, heart mass progressively increases secondary to cardiomyocyte hypertrophy associated with de novo sarcomeric protein synthesis (cardiac hypertrophic remodelling). This remodelling allows the cardiac chambers to cope with their increased load and is mandatory to prevent rupture of the heart, as predicted by Laplace's law. This remodelling requires a substantial and persistent anabolism, since heart mass can often increase by more than twofold in end-stage heart failure. Second, low cardiac output and arterial pressure chronically activate the renin-angiotensin-aldosterone system (RAAS) and sympathetic system, which alters cardiac nutrient supply by activating liver gluconeogenesis and ketogenesis, adipose tissue lipolysis and skeletal muscle protein degradation ${ }^{147}$. Moreover, increased RAAS signalling and

adrenergic tonus lead to the activation of HIF, mTOR and NF- $\kappa B$ signalling ${ }^{126,148,149}$, which can repress PPAR $\alpha^{150,151}$ and PPAR $\delta^{152}$ expression and activity, and activate PPAR $\gamma$ expression $^{148}$ (Fig. 2). These modified expression levels of genes encoding proteins involved in cardiac metabolism are reminiscent of the 'fetal cardiac phenotype'. This phenotype is characterized by low expression of genes encoding proteins involved in fatty acid uptake and mitochondrial catabolism and high expression of genes encoding proteins involved in glucose uptake, glycolysis, and glycogen and lipid storage, accompanied by high glucose-6-phosphate and aspartate concentrations ${ }^{127,153}$, which feed anabolic reactions for hypertrophy. The return 
to a fetal-like phenotype is also characterized by re-expression of specific contractile protein isoforms ( $\alpha$-actin and $\beta$-MHC) and natriuretic peptides and decreased sarcoplasmic/endoplasmic reticulum $\mathrm{Ca}^{2+}$ ATPase 2 expression ${ }^{148}$. Overall, the failing heart prefers glucose $\mathrm{e}^{154}$, lactate and ketone bodies ${ }^{155}$ for energy supply, while fatty acid uptake and mitochondrial oxidation proportionally decrease, which might lead to the accumulation of mitochondrial (mito)-toxic lipids (diacylglycerol and ceramides) ${ }^{156}$. Finally, the low oxidative phosphorylation capacity, combined with PPAR $\alpha$ and PPAR $\delta$ repression, results in a poor metabolic reserve with decreased cardiomyocyte high-energy phosphate content and poor contractile performance during exercise ${ }^{157}$.

Importantly, the current paradigm of energy metabolism disruption in heart failure is based on clinical studies involving patients with compensated chronic heart failure secondary to either hypertrophic cardiomyopathy ${ }^{158}$ or idiopathic dilated ${ }^{159}$ or ischaemic $^{155}$ cardiomyopathy with reduced left ventricular ejection fraction $(\sim 30 \%)$. According to rodent studies, a progressive worsening of cardiac metabolism occurs from early to end-stage heart failure $^{160}$. Further studies to determine whether this progressive worsening of cardiac metabolism occurs in patients with heart failure are warranted. Moreover, specific studies exploring myocardial metabolism in acute heart failure or in the growing phenogroup of chronic heart failure with preserved left ventricular ejection fraction have not yet been performed.

\section{Diabetic cardiomyopathy}

Even in the absence of overt clinical heart failure, patients with diabetes have alterations in myocardial structure, metabolism and energetics. These alterations include low glucose uptake and elevated FAO that is not suppressed by insulin ${ }^{159,161}$, intra-cardiomyocyte lipid droplet accumulation $^{158}$, mitochondrial network fission and dysfunction ${ }^{162}$, low high-energy phosphate 
content that further decreases during exercise ${ }^{163}$, concentric left ventricular remodelling and subtle contractile dysfunction ${ }^{158}$. This specific phenotype, referred to as diabetic cardiomyopathy, is thought to underlie the increased risk of heart failure in patients with diabetes, even after adjustment for other classic risk factors (such as coronary artery disease and hypertension).

Consistent with the observation that cardiac-restricted PPAR $\alpha$ overexpression mimics the diabetic heart phenotype, chronic activation of cardiomyocyte PPAR $\alpha$ by high circulating levels of free fatty acids, in combination with other non-PPAR related mechanisms (such as protein $O$-GlcNAcylation, protein kinase $\mathrm{C}$ and AMPK signalling), is probably a master switch in diabetic cardiomyopathy ${ }^{164}$. PPAR $\alpha$-mediated induction of genes encoding proteins involved in fatty acid uptake and oxidation, together with low expression of genes encoding proteins involved in glucose transport and glycolysis, promotes a vicious cycle of imbalance between fatty acid uptake and oxidation, accumulation of mitotoxic lipids, mitochondrial fatty acid (versus pyruvate) oxidation with high levels reactive oxygen species production, mitochondrial uncoupling and mitochondrial fission ${ }^{130,162}$. These events cause an inability to maintain high-energy phosphate content, that is, ATP starvation, despite nutrient overflow. PPAR $\gamma$ overexpression in combination with intra-myocardial lipid accumulation has been observed in left ventricular biopsy samples from patients with metabolic syndrome, which might also contribute to diabetic cardiomyopathy ${ }^{165}$.

Importantly, these alterations largely reflect the early metabolic changes related to systemic insulin resistance. Whether high rates of FAO are maintained or decreased in later stages of cardiac dysfunction related to diabetes, as occurs in the ischaemic heart, remains to be determined.

\section{PPARs: targets in heart failure?}


Failing heart are characterized by high levels of glucose uptake dedicated to anabolism rather than fuelling mitochondria with pyruvate and cytotoxic fatty acid accumulation (triglyceride, diacylglycerol and ceramides) secondary to an imbalance between fatty acid uptake and catabolism by dysfunctional mitochondria. Despite being favourable for the biosynthesis of cardiomyocyte material, this fetal-like metabolism, driven partly by low PPAR $\alpha$ and PPAR $\delta$ activity, also induces ATP starvation and a low metabolic reserve. Furthermore, increasing FAO by deleting Acacb, encoding acetyl-CoA-carboxylase 2, prevented cardiac remodelling, owing to glucose-induced aspartate synthesis, in phenylephrine-stimulated cardiomyocytes in vitro and in a pressure overload-induced cardiac hypertrophy model in vivo ${ }^{127}$. Moreover, preservation of FAO prevented the shift of metabolic flux to the anabolic pathway, promoting catabolic metabolism for energy production, thereby preventing cardiac hypertrophy and improving myocardial energetics ${ }^{127,166}$. Interestingly, induction of high levels of cardiac FAO in adult mice with tamoxifen-induced cardiac-specific Acacb deletion did not cause cardiac dysfunction but protected against cardiomyopathy in chronically obese mice, in part by maintaining mitochondrial function through regulating parkin-mediated mitophagy ${ }^{166}$. Therefore, it is tempting to hypothesize that increasing PPAR $\delta$ signalling, alone or in combination with PPAR $\alpha$ signalling, would rescue the failing heart by increasing mitochondrial oxidative phosphorylation capacity and specifically FAO.

However, very few studies have addressed this issue so far. Treatment with the PPAR $\delta$ agonist L-165041 prevented phenylephrine-induced hypertrophy of neonatal rat cardiomyocytes and its related fetal-like gene expression pattern in vitro, owing to PPAR $\delta$ transrepression of NF- $\kappa \mathrm{B}^{167}$. Constitutive activation of cardiac PPAR $\delta$ partially protected mice against pressure-overload mechanical stress induced by transaortic constriction, whereas constitutive PPAR $\delta$ activation did not modify heart mass or expression of molecular cardiac hypertrophy markers, such as atrial natriuretic factor, in the transaortic constriction mouse 
model $^{141}$. Instead, constitutive PPAR $\delta$ activation resulted in a less pronounced decrease in left ventricular ejection fraction and less pronounced myocardial fibrosis than in wild-type mice ${ }^{141}$.

By contrast, persistent PPAR $\alpha$ activation induces insulin resistance and causes lipid accumulation and lipotoxicity, a situation that mimics the diabetic heart ${ }^{168}$. However, with the use of an inducible transgenic mouse model and the PPAR $\alpha$ agonist WY-14643, Kaimoto and colleagues showed that short-term PPAR $\alpha$ activation early (2 weeks) after transaortic constriction maintained cardiac FAO, improved myocardial energetics and partially prevented cardiac remodelling in pressure-overload heart failure ${ }^{169}$. Agonist-mediated PPAR $\alpha$ activation in hypertrophied hearts resulted in severe impairment of cardiac function despite preventing the substrate switch in a rat model of cardiac pressure overload ${ }^{170}$. Long-term treatment with fenofibrate prevented the metabolic switch observed in pacing-induced heart failure in dogs, without altering the development of heart failure ${ }^{171}$.

\section{Future directions}

PPARs control various pathways at the systemic, vascular and cardiac levels, affecting risk factors for CVD and heart failure. PPAR $\alpha$ activation, primarily in the liver, reduces atherogenic dyslipidaemia and thereby has the potential to decrease post-statin residual risk in patients with dyslipidaemia. This hypothesis, generated by post-hoc analysis of several fibrate trials, is currently being tested in the PROMINENT trial ${ }^{119}$. PPAR $\gamma$ improves glucose metabolism by increasing insulin sensitivity and vascular function. Although glitazones might precipitate heart failure in high-risk patients by putting an increased preload on the failing heart, these drugs decrease the risk of myocardial infarction and stroke in secondary prevention patients with insulin-resistance, according to data from the IRIS trial ${ }^{114}$. Although PPAR $\delta$ agonists have not yet been tested in outcome trials, all PPARs might affect CVD and heart failure through complex systemic actions that modulate cardiovascular risk factors and improve NASH, which 
is an increasing health problem and a cardiovascular risk factor ${ }^{172}$. Interestingly, several dualPPAR and pan-PPAR agonists are being tested in clinical trials, currently mainly in patients with NAFLD ${ }^{173}$.

Whether lipid accumulation in the failing heart is caused by increased fatty acid uptake, increased triglyceride synthesis or decreased lipid degradation is currently uncertain. Whereas the accumulation of selective bioactive lipids, such as diacylglycerol and ceramides, might provoke cardiomyocyte toxicity, the dynamic shuttling of fatty acid in cardiomyocytes between cellular uptake, lipid droplet triglyceride accumulation and mitochondrial oxidation is necessary for proper cardiac function ${ }^{156,174}$. Moreover, fatty acids released by triglyceride lipolysis are natural PPAR ligands, and their turnover also maintains the expression of PPAR target genes in the failing heart ${ }^{175,176}$.

Evidence suggests that the healthy heart consumes ketone bodies in direct proportionality to their circulating levels and that the failing heart becomes more reliant on ketone bodies as a fuel ${ }^{155,177}$. Moreover, increasing the delivery of ketone bodies to the heart can prevent or reduce heart failure in preclinical models ${ }^{178}$. The beneficial effect of sodiumglucose cotransporter 2 inhibitors on the incidence of heart failure might be explained, at least in part, by their effect on cardiac substrate utilization ${ }^{179}$, that is, their promotion of ketogenesis and ketone body utilization ${ }^{180,181}$. Given that hepatic ketogenesis is driven by PPAR $\alpha$, the activation of PPAR $\alpha$ in the liver might be hypothesized to be beneficial in heart failure and warrants further study.

Although the differential functions of PPAR $\alpha$ and PPAR $\delta$ require further investigation, downregulation of cardiac PPAR $\alpha$ and PPAR $\delta$ activity seems to be a 'necessary evil' during heart failure to allow the heart to adapt to the increased myocardial wall stress by promoting anabolic hypertrophic response pathways necessary for cardiac protection. Although sustained, cardiac-restricted PPAR $\alpha$ activation seems inappropriate, treatment with a selective PPAR $\delta$ 
agonist or a dual PPAR $\alpha-\operatorname{PPAR} \delta$ agonist might be a promising method to boost cardiac mitochondrial function. Rescuing PPAR $\delta$, possibly with PPAR $\alpha$, particularly in the early stages of cardiac remodelling, could be a promising therapeutic strategy that warrants clinical testing.

\section{Conclusions}

The biology of the PPARs has proven to be complex and exciting. Several areas of research, such as PPAR regulation of inter-organ crosstalk, sex-specific PPAR actions and circadian control of PPAR activity, warrant further attention. These areas might be major determinants of optimal pharmacological responses to treatment with PPAR agonists. Further studies on the PPAR transcription factors in relation to heart disease are therefore warranted.

\section{References}

1. Cardiovascular diseases (CVDs). https://www.who.int/news-room/factsheets/detail/cardiovascular-diseases-(cvds).

2. Staels, B., Maes, M. \& Zambon, A. Fibrates and future PPARalpha agonists in the treatment of cardiovascular disease. Nat Clin Pract Cardiovasc Med 5, 542-553 (2008).

3. Gross, B., Pawlak, M., Lefebvre, P. \& Staels, B. PPARs in obesity-induced T2DM, dyslipidaemia and NAFLD. Nat Rev Endocrinol 13, 36-49 (2017).

4. Feige, J. N. \& Auwerx, J. Transcriptional coregulators in the control of energy homeostasis. Trends Cell Biol 17, 292-301 (2007).

5. Pawlak, M., Lefebvre, P. \& Staels, B. Molecular mechanism of PPAR $\alpha$ action and its impact on lipid metabolism, inflammation and fibrosis in non-alcoholic fatty liver disease. J. Hepatol. 62, 720-733 (2015).

6. Oishi, Y. et al. Krüppel-like transcription factor KLF5 is a key regulator of adipocyte differentiation. Cell Metab 1, 27-39 (2005). 
7. Lee, H. et al. Krüppel-Like Factor KLF8 Plays a Critical Role in Adipocyte Differentiation. PLoS One 7, (2012).

8. Liu, Y. et al. Krüppel-like factor 10 (KLF10) is transactivated by the transcription factor C/EBP and involved in early 3T3-L1 preadipocyte differentiation. J Biol Chem 293, 14012-14021 (2018).

9. Drosatos, K. et al. Cardiac Myocyte KLF5 Regulates Ppara Expression and Cardiac Function. Circ $\operatorname{Res} 118,241-253$ (2016).

10. Prosdocimo, D. A. et al. KLF15 and PPAR $\alpha$ Cooperate to Regulate Cardiomyocyte Lipid Gene Expression and Oxidation. PPAR Res 2015, (2015).

11. Oishi, Y. et al. SUMOylation of Krüppel-like transcription factor 5 acts as a molecular switch in transcriptional programs of lipid metabolism involving PPAR-delta. Nat Med 14, 656-666 (2008).

12. Dubois, V., Eeckhoute, J., Lefebvre, P. \& Staels, B. Distinct but complementary contributions of PPAR isotypes to energy homeostasis. J. Clin. Invest. 127, 1202-1214 (2017).

13. Bougarne, N. et al. Molecular Actions of PPAR $\alpha$ in Lipid Metabolism and Inflammation. Endocr. Rev. 39, 760-802 (2018).

14. Sasaki, Y. et al. Pemafibrate, a selective PPAR $\alpha$ modulator, prevents non-alcoholic steatohepatitis development without reducing the hepatic triglyceride content. Sci Rep 10, 7818 (2020).

15. Choi, Y.-J. et al. Effects of the PPAR- $\delta$ agonist MBX-8025 on atherogenic dyslipidemia. Atherosclerosis 220, 470-476 (2012).

16. Rastogi, A. et al. Abrogation of postprandial triglyceridemia with dual PPAR $\alpha / Y$ agonist in type 2 diabetes mellitus: a randomized, placebo-controlled study. Acta Diabetol 57, 809-818 (2020).

17. Ratziu, V. et al. Elafibranor, an Agonist of the Peroxisome Proliferator-Activated Receptor- $\alpha$ and $\delta$, Induces Resolution of Nonalcoholic Steatohepatitis Without Fibrosis Worsening. Gastroenterology 150, 1147-1159.e5 (2016).

18. Lefere, S. et al. Differential effects of selective- and pan-PPAR agonists on experimental steatohepatitis and hepatic macrophages $\mathfrak{z}^{2}$ J. Hepatol. (2020) doi:10.1016/j.jhep.2020.04.025. 
19. He, B. K. et al. In Vitro and In Vivo Characterizations of Chiglitazar, a Newly Identified PPAR PanAgonist. PPAR Res 2012, 546548 (2012).

20. Grabacka, M., Pierzchalska, M., Dean, M. \& Reiss, K. Regulation of Ketone Body Metabolism and the Role of PPARa. Int J Mol Sci 17, (2016).

21. Guan, D. et al. Diet-Induced Circadian Enhancer Remodeling Synchronizes Opposing Hepatic Lipid Metabolic Processes. Cell 174, 831-842.e12 (2018).

22. Drosatos, K. et al. Peroxisome proliferator-activated receptor- $\gamma$ activation prevents sepsisrelated cardiac dysfunction and mortality in mice. Circ Heart Fail 6, 550-562 (2013).

23. Paumelle, R. et al. Hepatic PPARa is critical in the metabolic adaptation to sepsis. J. Hepatol. 70, 963-973 (2019).

24. Seok, S. et al. Fasting-induced JMJD3 histone demethylase epigenetically activates mitochondrial fatty acid $\beta$-oxidation. J. Clin. Invest. 128, 3144-3159 (2018).

25. lershov, A. et al. The class 3 PI3K coordinates autophagy and mitochondrial lipid catabolism by controlling nuclear receptor PPAR $\alpha$. Nat Commun 10, 1566 (2019).

26. Zhao, Z. et al. Hepatic PPARa function is controlled by polyubiquitination and proteasomemediated degradation through the coordinated actions of PAQR3 and HUWE1. Hepatology 68, 289-303 (2018).

27. Francque, S. M., van der Graaff, D. \& Kwanten, W. J. Non-alcoholic fatty liver disease and cardiovascular risk: Pathophysiological mechanisms and implications. J. Hepatol. 65, 425-443 (2016).

28. Francque, S. et al. PPAR $\alpha$ gene expression correlates with severity and histological treatment response in patients with non-alcoholic steatohepatitis. J. Hepatol. 63, 164-173 (2015).

29. Liang, N. et al. Hepatocyte-specific loss of GPS2 in mice reduces non-alcoholic steatohepatitis via activation of PPARa. Nat Commun 10, 1684 (2019).

30. Montagner, A. et al. Liver PPAR $\alpha$ is crucial for whole-body fatty acid homeostasis and is protective against NAFLD. Gut 65, 1202-1214 (2016). 
31. Stec, D. E. et al. Loss of hepatic PPAR $\alpha$ promotes inflammation and serum hyperlipidemia in dietinduced obesity. Am. J. Physiol. Regul. Integr. Comp. Physiol. 317, R733-R745 (2019).

32. Régnier, M. et al. Hepatocyte-specific deletion of Ppara promotes NAFLD in the context of obesity. Sci Rep 10, 6489 (2020).

33. Brocker, C. N. et al. Extrahepatic PPAR $\alpha$ modulates fatty acid oxidation and attenuates fastinginduced hepatosteatosis in mice. J. Lipid Res. 59, 2140-2152 (2018).

34. Gaich, G. et al. The effects of LY2405319, an FGF21 analog, in obese human subjects with type 2 diabetes. Cell Metabolism 18, 333-340 (2013).

35. Sanyal, A. et al. Pegbelfermin (BMS-986036), a PEGylated fibroblast growth factor 21 analogue, in patients with non-alcoholic steatohepatitis: a randomised, double-blind, placebo-controlled, phase 2a trial. Lancet (London, England) 392, 2705-2717 (2019).

36. Zarei, M., Pizarro-Delgado, J., Barroso, E., Palomer, X. \& Vázquez-Carrera, M. Targeting FGF21 for the Treatment of Nonalcoholic Steatohepatitis. Trends in Pharmacological Sciences 41, 199208 (2020).

37. Hennuyer, N. et al. The novel selective PPAR $\alpha$ modulator (SPPARM $\alpha$ ) pemafibrate improves dyslipidemia, enhances reverse cholesterol transport and decreases inflammation and atherosclerosis. Atherosclerosis 249, 200-208 (2016).

38. Sairyo, M. et al. A Novel Selective PPAR $\alpha$ Modulator (SPPARM $\alpha$ ), K-877 (Pemafibrate), Attenuates Postprandial Hypertriglyceridemia in Mice. J. Atheroscler. Thromb. 25, 142-152 (2018).

39. Othman, A. et al. Fenofibrate lowers atypical sphingolipids in plasma of dyslipidemic patients: A novel approach for treating diabetic neuropathy? J Clin Lipidol 9, 568-575 (2015).

40. Holm, L. J. et al. Fenofibrate increases very-long-chain sphingolipids and improves blood glucose homeostasis in NOD mice. Diabetologia 62, 2262-2272 (2019). 
41. Keech, A. et al. Effects of long-term fenofibrate therapy on cardiovascular events in 9795 people with type 2 diabetes mellitus (the FIELD study): randomised controlled trial. Lancet 366, 1849$1861(2005)$.

42. ACCORD Study Group et al. Effects of combination lipid therapy in type 2 diabetes mellitus. $N$. Engl. J. Med. 362, 1563-1574 (2010).

43. Gutiérrez-Cuevas, J. et al. Prolonged-release pirfenidone prevents obesity-induced cardiac steatosis and fibrosis in a mouse NASH model. Cardiovasc Drugs Ther (2020) doi:10.1007/s10557-020-07014-9.

44. Barroso, E. et al. The PPAR $\beta / \delta$ activator GW501516 prevents the down-regulation of AMPK caused by a high-fat diet in liver and amplifies the PGC-1 $\alpha$-Lipin 1-PPAR $\alpha$ pathway leading to increased fatty acid oxidation. Endocrinology 152, 1848-1859 (2011).

45. Zarei, M. et al. Hepatic regulation of VLDL receptor by PPARß/ $\delta$ and FGF21 modulates nonalcoholic fatty liver disease. Mol Metab 8, 117-131 (2018).

46. Wolf Greenstein, A. et al. Hepatocyte-specific, PPARY-regulated mechanisms to promote steatosis in adult mice. J. Endocrinol. 232, 107-121 (2017).

47. Li, X. et al. microRNA-34a and microRNA-34c promote the activation of human hepatic stellate cells by targeting peroxisome proliferator-activated receptor $\gamma$. Mol Med Rep 11, 1017-1024 (2015).

48. Oikonomou, E. K. \& Antoniades, C. The role of adipose tissue in cardiovascular health and disease. Nat Rev Cardiol 16, 83-99 (2019).

49. Ha, E. E. \& Bauer, R. C. Emerging Roles for Adipose Tissue in Cardiovascular Disease. Arterioscler. Thromb. Vasc. Biol. 38, e137-e144 (2018).

50. Dean, J. M. et al. MED19 Regulates Adipogenesis and Maintenance of White Adipose Tissue Mass by Mediating PPARY-Dependent Gene Expression. Cell Rep 33, 108228 (2020).

51. El Ouarrat, D. et al. TAZ Is a Negative Regulator of PPARY Activity in Adipocytes and TAZ Deletion Improves Insulin Sensitivity and Glucose Tolerance. Cell Metab. 31, 162-173.e5 (2020). 
52. Fujiki, K. et al. PPARY-induced PARylation promotes local DNA demethylation by production of 5-hydroxymethylcytosine. Nat Commun 4, 2262 (2013).

53. Bian, F. et al. TET2 facilitates PPARy agonist-mediated gene regulation and insulin sensitization in adipocytes. Metab. Clin. Exp. 89, 39-47 (2018).

54. Peng, J. et al. An Hsp20-FBXO4 Axis Regulates Adipocyte Function through Modulating PPARy Ubiquitination. Cell Rep 23, 3607-3620 (2018).

55. Virtue, S. et al. Peroxisome Proliferator-Activated Receptor 12 Controls the Rate of Adipose Tissue Lipid Storage and Determines Metabolic Flexibility. Cell Rep 24, 2005-2012.e7 (2018).

56. Katafuchi, T. et al. PPARY-K107 SUMOylation regulates insulin sensitivity but not adiposity in mice. Proc Natl Acad Sci U S A 115, 12102-12111 (2018).

57. Bastie, C., Luquet, S., Holst, D., Jehl-Pietri, C. \& Grimaldi, P. A. Alterations of peroxisome proliferator-activated receptor delta activity affect fatty acid-controlled adipose differentiation. J Biol Chem 275, 38768-38773 (2000).

58. Kang, K. et al. Adipocyte-derived Th2 cytokines and myeloid PPARdelta regulate macrophage polarization and insulin sensitivity. Cell Metabolism 7, 485-495 (2008).

59. Wang, Y.-X. et al. Peroxisome-proliferator-activated receptor delta activates fat metabolism to prevent obesity. Cell 113, 159-170 (2003).

60. Doktorova, M. et al. Intestinal PPARס protects against diet-induced obesity, insulin resistance and dyslipidemia. Sci Rep 7, 846 (2017).

61. Bays, H. E. et al. MBX-8025, a novel peroxisome proliferator receptor-delta agonist: lipid and other metabolic effects in dyslipidemic overweight patients treated with and without atorvastatin. The Journal of Clinical Endocrinology and Metabolism 96, 2889-2897 (2011).

62. Qiang, L. et al. Brown remodeling of white adipose tissue by SirT1-dependent deacetylation of Ppary. Cell 150, 620-632 (2012).

63. Hall, J. A. et al. Obesity-Linked PPARY S273 Phosphorylation Promotes Insulin Resistance through Growth Differentiation Factor 3. Cell Metab 32, 665-675.e6 (2020). 
64. Kraakman, M. J. et al. PPARy deacetylation dissociates thiazolidinedione's metabolic benefits from its adverse effects. J. Clin. Invest. 128, 2600-2612 (2018).

65. Barbera, M. J. et al. Peroxisome proliferator-activated receptor alpha activates transcription of the brown fat uncoupling protein-1 gene. A link between regulation of the thermogenic and lipid oxidation pathways in the brown fat cell. The Journal of Biological Chemistry 276, 1486-1493 (2001).

66. Hondares, E. et al. Peroxisome proliferator-activated receptor $\alpha$ (PPAR $\alpha$ ) induces PPARY coactivator $1 \alpha$ (PGC-1 $\alpha$ ) gene expression and contributes to thermogenic activation of brown fat: involvement of PRDM16. The Journal of Biological Chemistry 286, 43112-43122 (2011).

67. Rachid, T. L. et al. Fenofibrate (PPARalpha agonist) induces beige cell formation in subcutaneous white adipose tissue from diet-induced male obese mice. Molecular and Cellular Endocrinology 402, 86-94 (2015).

68. Zhou, L. et al. Coordination Among Lipid Droplets, Peroxisomes, and Mitochondria Regulates Energy Expenditure Through the CIDE-ATGL-PPARa Pathway in Adipocytes. Diabetes 67, 19351948 (2018).

69. Jeong, S. et al. Effects of fenofibrate on high-fat diet-induced body weight gain and adiposity in female C57BL/6J mice. Metabolism: Clinical and Experimental 53, 1284-1289 (2004).

70. Xiong, W. et al. Brown Adipocyte-Specific PPARY (Peroxisome Proliferator-Activated Receptor $\gamma$ ) Deletion Impairs Perivascular Adipose Tissue Development and Enhances Atherosclerosis in Mice. Arterioscler. Thromb. Vasc. Biol. 38, 1738-1747 (2018).

71. Nauck, M. A., Meier, J. J., Cavender, M. A., Abd El Aziz, M. \& Drucker, D. J. Cardiovascular Actions and Clinical Outcomes With Glucagon-Like Peptide-1 Receptor Agonists and Dipeptidyl Peptidase-4 Inhibitors. Circulation 136, 849-870 (2017).

72. Marx, N. Reduction of cardiovascular risk in patients with T2DM by GLP-1 receptor agonists: a shift in paradigm driven by data from large cardiovascular outcome trials. Eur Heart J 41, 3359$3362(2020)$. 
73. Tang, W. H. W., Kitai, T. \& Hazen, S. L. Gut Microbiota in Cardiovascular Health and Disease. Circ. Res. 120, 1183-1196 (2017).

74. den Besten, G. et al. Short-Chain Fatty Acids Protect Against High-Fat Diet-Induced Obesity via a PPARY-Dependent Switch From Lipogenesis to Fat Oxidation. Diabetes 64, 2398-2408 (2015).

75. Nepelska, M. et al. Commensal gut bacteria modulate phosphorylation-dependent PPARY transcriptional activity in human intestinal epithelial cells. Sci Rep 7, 43199 (2017).

76. Byndloss, M. X. et al. Microbiota-activated PPAR- $y$ signaling inhibits dysbiotic Enterobacteriaceae expansion. Science 357, 570-575 (2017).

77. Tomas, J. et al. High-fat diet modifies the PPAR- $\gamma$ pathway leading to disruption of microbial and physiological ecosystem in murine small intestine. Proc. Natl. Acad. Sci. U.S.A. 113, E5934-E5943 (2016).

78. Duszka, K. et al. Complementary intestinal mucosa and microbiota responses to caloric restriction. Sci Rep 8, 11338 (2018).

79. Colin, S. et al. Activation of intestinal peroxisome proliferator-activated receptor- $\alpha$ increases high-density lipoprotein production. Eur. Heart J. 34, 2566-2574 (2013).

80. Takei, K. et al. Effects of K-877, a novel selective PPAR $\alpha$ modulator, on small intestine contribute to the amelioration of hyperlipidemia in low-density lipoprotein receptor knockout mice. J. Pharmacol. Sci. 133, 214-222 (2017).

81. Daoudi, M. et al. PPAR $\beta / \delta$ activation induces enteroendocrine L cell GLP-1 production. Gastroenterology 140, 1564-1574 (2011).

82. Luquet, S. et al. Peroxisome proliferator-activated receptor delta controls muscle development and oxidative capability. FASEB J. 17, 2299-2301 (2003).

83. Wang, Y.-X. et al. Regulation of muscle fiber type and running endurance by PPARdelta. PLoS Biol. 2, e294 (2004). 
84. Koh, J.-H. et al. PPAR $\beta$ Is Essential for Maintaining Normal Levels of PGC-1 $\alpha$ and Mitochondria and for the Increase in Muscle Mitochondria Induced by Exercise. Cell Metab. 25, 1176-1185.e5 (2017).

85. Koh, J.-H. et al. AMPK and PPAR $\beta$ positive feedback loop regulates endurance exercise trainingmediated GLUT4 expression in skeletal muscle. Am. J. Physiol. Endocrinol. Metab. 316, E931E939 (2019).

86. Le Garf, S. et al. Complementary Immunometabolic Effects of Exercise and PPAR $\beta / \delta$ Agonist in the Context of Diet-Induced Weight Loss in Obese Female Mice. Int J Mol Sci 20, (2019).

87. Fan, W. et al. PPARס Promotes Running Endurance by Preserving Glucose. Cell Metab. 25, 11861193.e4 (2017).

88. Finck, B. N. et al. A potential link between muscle peroxisome proliferator- activated receptoralpha signaling and obesity-related diabetes. Cell Metab. 1, 133-144 (2005).

89. Bhattacharjee, S., Das, N., Mandala, A., Mukhopadhyay, S. \& Roy, S. S. Fenofibrate Reverses Palmitate Induced Impairment in Glucose Uptake in Skeletal Muscle Cells by Preventing Cytosolic Ceramide Accumulation. Cell. Physiol. Biochem. 37, 1315-1328 (2015).

90. Libby, P. et al. Atherosclerosis. Nat Rev Dis Primers 5, 56 (2019).

91. Mundi, S. et al. Endothelial permeability, LDL deposition, and cardiovascular risk factors-a review. Cardiovasc. Res. 114, 35-52 (2018).

92. Marx, N., Duez, H., Fruchart, J.-C. \& Staels, B. Peroxisome proliferator-activated receptors and atherogenesis: regulators of gene expression in vascular cells. Circ. Res. 94, 1168-1178 (2004).

93. De Silva, T. M., Li, Y., Kinzenbaw, D. A., Sigmund, C. D. \& Faraci, F. M. Endothelial PPARy (Peroxisome Proliferator-Activated Receptor- $\gamma$ ) Is Essential for Preventing Endothelial Dysfunction With Aging. Hypertension 72, 227-234 (2018).

94. Li, C. G. et al. PPARY Interaction with UBR5/ATMIN Promotes DNA Repair to Maintain Endothelial Homeostasis. Cell Rep 26, 1333-1343.e7 (2019). 
95. Mao, H. et al. Endothelial LRP1 regulates metabolic responses by acting as a co-activator of PPARy. Nat Commun 8, 14960 (2017).

96. Calvier, L. et al. PPARy Links BMP2 and TGFß1 Pathways in Vascular Smooth Muscle Cells, Regulating Cell Proliferation and Glucose Metabolism. Cell Metab. 25, 1118-1134.e7 (2017).

97. Yu, J. et al. DNMT1-PPARY pathway in macrophages regulates chronic inflammation and atherosclerosis development in mice. Sci Rep 6, 30053 (2016).

98. Bouhlel, M. A. et al. PPARgamma activation primes human monocytes into alternative M2 macrophages with anti-inflammatory properties. Cell Metabolism 6, 137-143 (2007).

99. Nelson, V. L. et al. PPARy is a nexus controlling alternative activation of macrophages via glutamine metabolism. Genes Dev. 32, 1035-1044 (2018).

100. Jordan, S. et al. Dietary Intake Regulates the Circulating Inflammatory Monocyte Pool. Cell 178, 1102-1114.e17 (2019).

101. Barish, G. D. et al. PPARdelta regulates multiple proinflammatory pathways to suppress atherosclerosis. Proc. Natl. Acad. Sci. U.S.A. 105, 4271-4276 (2008).

102. Tian, X. Y. et al. PPARס activation protects endothelial function in diabetic mice. Diabetes 61, 3285-3293 (2012).

103. Toral, M. et al. Role of UCP2 in the protective effects of PPARß/ $\delta$ activation on lipopolysaccharide-induced endothelial dysfunction. Biochem. Pharmacol. 110-111, 25-36 (2016).

104. Fang, X. et al. Activation of PPAR- $\delta$ induces microRNA-100 and decreases the uptake of very lowdensity lipoprotein in endothelial cells. Br. J. Pharmacol. 172, 3728-3736 (2015).

105. Hwang, J. S. et al. Sirtuin 1 Mediates the Actions of Peroxisome Proliferator-Activated Receptor $\delta$ on the Oxidized Low-Density Lipoprotein-Triggered Migration and Proliferation of Vascular Smooth Muscle Cells. Mol. Pharmacol. 90, 522-529 (2016). 
106. Yue Tian-li et al. In Vivo Myocardial Protection From Ischemia/Reperfusion Injury by the Peroxisome Proliferator-Activated Receptor- $\gamma$ Agonist Rosiglitazone. Circulation 104, 25882594 (2001).

107. Yue, T. et al. Activation of peroxisome proliferator-activated receptor-alpha protects the heart from ischemia/reperfusion injury. Circulation 108, 2393-2399 (2003).

108. Kapoor, A., Collino, M., Castiglia, S., Fantozzi, R. \& Thiemermann, C. Activation of peroxisome proliferator-activated receptor-beta/delta attenuates myocardial ischemia/reperfusion injury in the rat. Shock 34, 117-124 (2010).

109. el Azzouzi, H. et al. Peroxisome proliferator-activated receptor (PPAR) gene profiling uncovers insulin-like growth factor-1 as a PPARalpha target gene in cardioprotection. J Biol Chem 286, 14598-14607 (2011).

110. Yue, T.-L. et al. Rosiglitazone treatment in Zucker diabetic Fatty rats is associated with ameliorated cardiac insulin resistance and protection from ischemia/reperfusion-induced myocardial injury. Diabetes 54, 554-562 (2005).

111. Morrison, A., Yan, X., Tong, C. \& Li, J. Acute rosiglitazone treatment is cardioprotective against ischemia-reperfusion injury by modulating AMPK, Akt, and JNK signaling in nondiabetic mice. American Journal of Physiology-Heart and Circulatory Physiology 301, H895-H902 (2011).

112. Xiang, A. H. et al. Effect of pioglitazone on pancreatic beta-cell function and diabetes risk in Hispanic women with prior gestational diabetes. Diabetes 55, 517-522 (2006).

113. Dormandy, J. A. et al. Secondary prevention of macrovascular events in patients with type 2 diabetes in the PROactive Study (PROspective pioglitAzone Clinical Trial In macroVascular Events): a randomised controlled trial. Lancet 366, 1279-1289 (2005).

114. Kernan, W. N. et al. Pioglitazone after Ischemic Stroke or Transient Ischemic Attack. N. Engl. J. Med. 374, 1321-1331 (2016).

115. Kalliora, C. et al. Dual peroxisome-proliferator-activated-receptor- $\alpha / \gamma$ activation inhibits SIRT1PGC1 $\alpha$ axis and causes cardiac dysfunction. JCI Insight 5, (2019). 
116. Duan, S. Z., Ivashchenko, C. Y., Russell, M. W., Milstone, D. S. \& Mortensen, R. M. Cardiomyocytespecific knockout and agonist of peroxisome proliferator-activated receptor-gamma both induce cardiac hypertrophy in mice. Circ Res 97, 372-379 (2005).

117. Sena, S. et al. Cardiac hypertrophy caused by peroxisome proliferator- activated receptorgamma agonist treatment occurs independently of changes in myocardial insulin signaling. Endocrinology 148, 6047-6053 (2007).

118. Barbieri, M. et al. Effects of PPARs agonists on cardiac metabolism in littermate and cardiomyocyte-specific PPAR- - -knockout (CM-PGKO) mice. PLoS One 7, e35999 (2012).

119. US National Library of Medicine. ClinicalTrials.gov. Pemafibrate to Reduce Cardiovascular OutcoMes by Reducing Triglycerides IN patiENts With diabeTes (PROMINENT) https://clinicaltrials.gov/ct2/show/NCT03071692. (2017).

120. Pradhan, A. D. et al. Rationale and design of the Pemafibrate to Reduce Cardiovascular Outcomes by Reducing Triglycerides in Patients with Diabetes (PROMINENT) study. Am. Heart J. 206, 80-93 (2018).

121. Araki, E. et al. Effects of Pemafibrate, a Novel Selective PPAR $\alpha$ Modulator, on Lipid and Glucose Metabolism in Patients With Type 2 Diabetes and Hypertriglyceridemia: A Randomized, DoubleBlind, Placebo-Controlled, Phase 3 Trial. Diabetes Care 41, 538-546 (2018).

122. Ishibashi, S. et al. Efficacy and safety of pemafibrate (K-877), a selective peroxisome proliferatoractivated receptor $\alpha$ modulator, in patients with dyslipidemia: Results from a 24-week, randomized, double blind, active-controlled, phase 3 trial. J Clin Lipidol 12, 173-184 (2018).

123. Madrazo, J. A. \& Kelly, D. P. The PPAR trio: regulators of myocardial energy metabolism in health and disease. J. Mol. Cell. Cardiol. 44, 968-975 (2008).

124. Pol, C. J., Lieu, M. \& Drosatos, K. PPARs: Protectors or Opponents of Myocardial Function? PPAR Res 2015, 835985 (2015).

125. Lehman, J. J. \& Kelly, D. P. Transcriptional activation of energy metabolic switches in the developing and hypertrophied heart. Clin. Exp. Pharmacol. Physiol. 29, 339-345 (2002). 
126. Mirtschink, P. \& Krek, W. Hypoxia-driven glycolytic and fructolytic metabolic programs: Pivotal to hypertrophic heart disease. Biochim. Biophys. Acta 1863, 1822-1828 (2016).

127. Ritterhoff, J. et al. Metabolic Remodeling Promotes Cardiac Hypertrophy by Directing Glucose to Aspartate Biosynthesis. Circ. Res. 126, 182-196 (2020).

128. Cluntun, A. A. et al. The pyruvate-lactate axis modulates cardiac hypertrophy and heart failure. Cell Metab (2020) doi:10.1016/j.cmet.2020.12.003.

129. Zhang, Y. et al. Mitochondrial pyruvate carriers are required for myocardial stress adaptation. Nat Metab 2, 1248-1264 (2020).

130. Cardoso, A. C. et al. Mitochondrial Substrate Utilization Regulates Cardiomyocyte Cell Cycle Progression. Nat Metab 2, 167-178 (2020).

131. Lopaschuk, G. D., Collins-Nakai, R. L. \& Itoi, T. Developmental changes in energy substrate use by the heart. Cardiovasc. Res. 26, 1172-1180 (1992).

132. Dorn, G. W., Vega, R. B. \& Kelly, D. P. Mitochondrial biogenesis and dynamics in the developing and diseased heart. Genes Dev. 29, 1981-1991 (2015).

133. Son, N.-H. et al. Cardiomyocyte expression of PPARgamma leads to cardiac dysfunction in mice. J. Clin. Invest. 117, 2791-2801 (2007).

134. Watanabe, K. et al. Constitutive regulation of cardiac fatty acid metabolism through peroxisome proliferator-activated receptor alpha associated with age-dependent cardiac toxicity. J. Biol. Chem. 275, 22293-22299 (2000).

135. Campbell, F. M. et al. A role for peroxisome proliferator-activated receptor alpha (PPARalpha ) in the control of cardiac malonyl-CoA levels: reduced fatty acid oxidation rates and increased glucose oxidation rates in the hearts of mice lacking PPARalpha are associated with higher concentrations of malonyl-CoA and reduced expression of malonyl-CoA decarboxylase. J. Biol. Chem. 277, 4098-4103 (2002). 
136. Leone, T. C., Weinheimer, C. J. \& Kelly, D. P. A critical role for the peroxisome proliferatoractivated receptor alpha (PPARalpha) in the cellular fasting response: the PPARalpha-null mouse as a model of fatty acid oxidation disorders. Proc. Natl. Acad. Sci. U.S.A. 96, 7473-7478 (1999).

137. Luptak, I. et al. Decreased contractile and metabolic reserve in peroxisome proliferator-activated receptor-alpha-null hearts can be rescued by increasing glucose transport and utilization. Circulation 112, 2339-2346 (2005).

138. Haemmerle, G. et al. ATGL-mediated fat catabolism regulates cardiac mitochondrial function via PPAR- $\alpha$ and PGC-1. Nature Medicine 17, 1076-1085 (2011).

139. Finck, B. N. et al. The cardiac phenotype induced by PPARalpha overexpression mimics that caused by diabetes mellitus. J. Clin. Invest. 109, 121-130 (2002).

140. Burkart, E. M. et al. Nuclear receptors PPARbeta/delta and PPARalpha direct distinct metabolic regulatory programs in the mouse heart. J. Clin. Invest. 117, 3930-3939 (2007).

141. Liu, J. et al. Peroxisome proliferator-activated receptor $\beta / \delta$ activation in adult hearts facilitates mitochondrial function and cardiac performance under pressure-overload condition. Hypertension 57, 223-230 (2011).

142. Cheng, L. et al. Cardiomyocyte-restricted peroxisome proliferator-activated receptor-delta deletion perturbs myocardial fatty acid oxidation and leads to cardiomyopathy. Nat. Med. 10, $1245-1250$ (2004).

143. Ding, G. et al. Cardiac peroxisome proliferator-activated receptor gamma is essential in protecting cardiomyocytes from oxidative damage. Cardiovasc Res 76, 269-279 (2007).

144. Son, N.-H. et al. PPARY-induced cardiolipotoxicity in mice is ameliorated by PPAR $\alpha$ deficiency despite increases in fatty acid oxidation. J Clin Invest 120, 3443-3454 (2010).

145. Bosma, M. et al. Sequestration of fatty acids in triglycerides prevents endoplasmic reticulum stress in an in vitro model of cardiomyocyte lipotoxicity. Biochim Biophys Acta 1841, 1648-1655 (2014). 
146. Bertero, E. \& Maack, C. Metabolic remodelling in heart failure. Nat Rev Cardiol 15, 457-470 (2018).

147. Wende, A. R., Brahma, M. K., McGinnis, G. R. \& Young, M. E. Metabolic Origins of Heart Failure. JACC Basic Trans/ Sci 2, 297-310 (2017).

148. Krishnan, J. et al. Activation of a HIF1alpha-PPARgamma axis underlies the integration of glycolytic and lipid anabolic pathways in pathologic cardiac hypertrophy. Cell Metab. 9, 512-524 (2009).

149. Shende, P. et al. Cardiac raptor ablation impairs adaptive hypertrophy, alters metabolic gene expression, and causes heart failure in mice. Circulation 123, 1073-1082 (2011).

150. Barger, P. M., Brandt, J. M., Leone, T. C., Weinheimer, C. J. \& Kelly, D. P. Deactivation of peroxisome proliferator-activated receptor-alpha during cardiac hypertrophic growth. J. Clin. Invest. 105, 1723-1730 (2000).

151. Cole, M. A. et al. On the pivotal role of PPAR $\alpha$ in adaptation of the heart to hypoxia and why fat in the diet increases hypoxic injury. FASEB J. 30, 2684-2697 (2016).

152. el Azzouzi, H. et al. The hypoxia-inducible microRNA cluster miR-199a 214 targets myocardial PPARס and impairs mitochondrial fatty acid oxidation. Cell Metab. 18, 341-354 (2013).

153. Tran, D. H. et al. Chronic activation of hexosamine biosynthesis in the heart triggers pathological cardiac remodeling. Nat Commun 11, 1771 (2020).

154. Neglia, D. et al. Impaired myocardial metabolic reserve and substrate selection flexibility during stress in patients with idiopathic dilated cardiomyopathy. Am. J. Physiol. Heart Circ. Physiol. 293, H3270-3278 (2007).

155. Murashige, D. et al. Comprehensive quantification of fuel use by the failing and nonfailing human heart. Science 370, 364-368 (2020).

156. Schulze, P. C., Drosatos, K. \& Goldberg, I. J. Lipid Use and Misuse by the Heart. Circ Res 118, 1736-1751 (2016). 
157. Dass, S. et al. Exacerbation of cardiac energetic impairment during exercise in hypertrophic cardiomyopathy: a potential mechanism for diastolic dysfunction. Eur. Heart J. 36, 1547-1554 (2015).

158. Levelt, E. et al. Relationship between Left Ventricular Structural and Metabolic Remodelling in Type 2 Diabetes Mellitus. Diabetes 65, 44-52 (2016).

159. Mather, K. J. et al. Assessment of myocardial metabolic flexibility and work efficiency in human type 2 diabetes using 16-[18F]fluoro-4-thiapalmitate, a novel PET fatty acid tracer. Am. J. Physiol. Endocrinol. Metab. 310, E452-460 (2016).

160. Kato, T. et al. Analysis of metabolic remodeling in compensated left ventricular hypertrophy and heart failure. Circ Heart Fail 3, 420-430 (2010).

161. McGill, J. B. et al. Potentiation of abnormalities in myocardial metabolism with the development of diabetes in women with obesity and insulin resistance. J Nucl Cardiol 18, 421-429; quiz 432433 (2011).

162. Montaigne, D. et al. Myocardial contractile dysfunction is associated with impaired mitochondrial function and dynamics in type 2 diabetic but not in obese patients. Circulation 130, 554-564 (2014).

163. Levelt, E. et al. Cardiac energetics, oxygenation, and perfusion during increased workload in patients with type 2 diabetes mellitus. Eur. Heart J. 37, 3461-3469 (2016).

164. Jia, G., Hill, M. A. \& Sowers, J. R. Diabetic Cardiomyopathy: An Update of Mechanisms Contributing to This Clinical Entity. Circ Res 122, 624-638 (2018).

165. Marfella, R. et al. Myocardial lipid accumulation in patients with pressure-overloaded heart and metabolic syndrome. J Lipid Res 50, 2314-2323 (2009).

166. Shao, D. et al. Increasing Fatty Acid Oxidation Prevents High-Fat Diet-Induced Cardiomyopathy Through Regulating Parkin-Mediated Mitophagy. Circulation 142, 983-997 (2020).

167. Planavila, A. et al. Peroxisome proliferator-activated receptor beta/delta activation inhibits hypertrophy in neonatal rat cardiomyocytes. Cardiovasc. Res. 65, 832-841 (2005). 
168. Park, S.-Y. et al. Cardiac-specific overexpression of peroxisome proliferator-activated receptoralpha causes insulin resistance in heart and liver. Diabetes 54, 2514-2524 (2005).

169. Kaimoto, S. et al. Activation of PPAR- $\alpha$ in the early stage of heart failure maintained myocardial function and energetics in pressure-overload heart failure. Am. J. Physiol. Heart Circ. Physiol. 312, H305-H313 (2017).

170. Young, M. E., Laws, F. A., Goodwin, G. W. \& Taegtmeyer, H. Reactivation of peroxisome proliferator-activated receptor alpha is associated with contractile dysfunction in hypertrophied rat heart. J. Biol. Chem. 276, 44390-44395 (2001).

171. Labinskyy, V. et al. Chronic activation of peroxisome proliferator-activated receptor-alpha with fenofibrate prevents alterations in cardiac metabolic phenotype without changing the onset of decompensation in pacing-induced heart failure. J. Pharmacol. Exp. Ther. 321, 165-171 (2007).

172. Deprince A, Haas JT, \& Staels B. Dysregulated lipid metabolism links NAFLD to cardiovascular disease. Molecular Metabolism (2020).

173. Berthier, A., Johanns, M., Zummo, F. P., Lefebvre, P. \& Staels, B. PPARs in liver physiology. Biochim Biophys Acta Mol Basis Dis 1867, 166097 (2021).

174. Carley, A. N. \& Lewandowski, E. D. Triacylglycerol turnover in the failing heart. Biochim Biophys Acta 1861, 1492-1499 (2016).

175. Banke, N. H. et al. Preferential oxidation of triacylglyceride-derived fatty acids in heart is augmented by the nuclear receptor PPARalpha. Circ Res 107, 233-241 (2010).

176. Lahey, R., Wang, X., Carley, A. N. \& Lewandowski, E. D. Dietary fat supply to failing hearts determines dynamic lipid signaling for nuclear receptor activation and oxidation of stored triglyceride. Circulation 130, 1790-1799 (2014).

177. Aubert, G. et al. The Failing Heart Relies on Ketone Bodies as a Fuel. Circulation 133, 698-705 (2016).

178. Horton, J. L. et al. The failing heart utilizes 3-hydroxybutyrate as a metabolic stress defense. JCI Insight 4, (2019). 
179. Cowie, M. R. \& Fisher, M. SGLT2 inhibitors: mechanisms of cardiovascular benefit beyond glycaemic control. Nature Reviews Cardiology 17, 761-772 (2020).

180. Ferrannini, E. et al. Shift to Fatty Substrate Utilization in Response to Sodium-Glucose Cotransporter 2 Inhibition in Subjects Without Diabetes and Patients With Type 2 Diabetes. Diabetes 65, 1190-1195 (2016).

181. Santos-Gallego, C. G. et al. Empagliflozin Ameliorates Adverse Left Ventricular Remodeling in Nondiabetic Heart Failure by Enhancing Myocardial Energetics. J Am Coll Cardiol 73, 1931-1944 (2019).

182. Li, X. et al. Treatment with PPAR $\delta$ agonist alleviates non-alcoholic fatty liver disease by modulating glucose and fatty acid metabolic enzymes in a rat model. Int J Mol Med 36, 767-775 (2015).

183. Soccio, R. E., Chen, E. R. \& Lazar, M. A. Thiazolidinediones and the promise of insulin sensitization in type 2 diabetes. Cell Metab 20, 573-591 (2014).

184. Lopaschuk, G. D., Ussher, J. R., Folmes, C. D. L., Jaswal, J. S. \& Stanley, W. C. Myocardial fatty acid metabolism in health and disease. Physiol Rev 90, 207-258 (2010).

185. Goodwin, G. W., Taylor, C. S. \& Taegtmeyer, H. Regulation of energy metabolism of the heart during acute increase in heart work. J. Biol. Chem. 273, 29530-29539 (1998).

186. Camici, P. et al. Coronary hemodynamics and myocardial metabolism during and after pacing stress in normal humans. Am. J. Physiol. 257, E309-317 (1989).

187. Bartelds, B. et al. Perinatal changes in myocardial metabolism in lambs. Circulation 102, 926931 (2000).

\section{Acknowledgements}

The authors are supported by grants from Agence Nationale pour la Recherche (ANR-16RHUS-0006-PreciNASH, "European Genomic Institute for Diabetes" E.G.I.D. ANR-10- 
LABX-0046 and ANR-16-IDEX-0004 ULNE, ANR TOMIS-Leukocyte: ANR-CE14-0003-01 and ANR CALMOS: ANR-18-CE17-0003-02), the Leducq Foundation LEAN Network 16CVD01 and the National Center for Precision Diabetic Medicine - PreciDIAB (ANR-18IBHU-0001; 20001891/NP0025517; 2019_ESR_11). B.S. is a recipient of an Advanced ERC Grant (694717).

\section{Author contributions}

All the authors contributed substantially to all aspects of preparing the manuscript.

\section{Competing interests}

B.S. is a consultant for Genfit. D.M. and L.B and declare no competing interests.

\section{Peer review information}

Nature Reviews Cardiology thanks K. Drosatos, D. Kelly, A. Murray and the other, anonymous, reviewer(s) for their contribution to the peer review of this work.

\section{Review criteria}

We have focused on original research articles published after 2017 covering the topics of cardiovascular risk factors, metabolism and new mechanisms of regulation by PPARs, because exhaustive reviews on PPARs functions covering the period before 2017 have previously been published. For the section on the role of PPARs in heart metabolism, we focus on studies showing the function of the PPARs in the heart.

\section{Key points}


Peroxisome proliferator-activated receptors (PPARs) are fatty acid sensors regulating wholebody metabolism.

Activation of PPAR $\gamma$ (for example, by glitazones) improves the management of diabetes mellitus by increasing insulin-sensitivity.

Activation of PPAR $\alpha$ (for example, by fibrates) normalizes atherogenic dyslipidaemia, thereby lowering the risk of cardiovascular disease.

PPARs are expressed in the heart, where they modulate lipid and glucose metabolism.

Failing or stressed hearts switch from the preferential use of fatty acids as energy substrates to glucose oxidation, with repression of the PPAR $\alpha$ and PPAR $\delta$ pathways.

Rescuing PPAR $\delta$ or both PPAR $\alpha$ and PPAR $\delta$ signalling, particularly in early stages of cardiac remodelling, might be a promising therapeutic strategy for heart failure. 
Table 1 | Single, dual and pan PPAR agonists

\begin{tabular}{|c|c|c|c|}
\hline Targets & Agonists & Reported biological effects & Refs \\
\hline PPAR $\alpha$ & 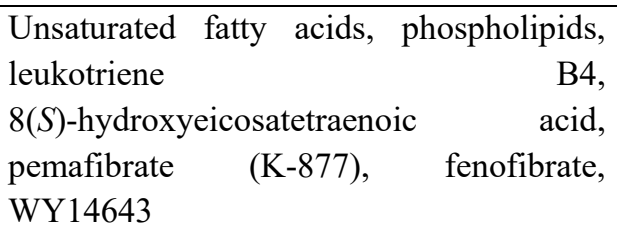 & $\begin{array}{l}\text { Improved lipid profile in patients } \\
\text { with dyslipidaemia }\end{array}$ & $14,41,42$ \\
\hline PPAR $\delta$ & $\begin{array}{l}\text { Unsaturated fatty acids, components of } \\
\text { VLDL, prostacyclin } \\
\text { 13(S)-hydroxyoctadecadienoic acid, } \\
\text { GW501516, seladelpar (MBX-8025), } \\
\text { L-165041 }\end{array}$ & $\begin{array}{l}\text { Improved lipid profile and insulin } \\
\text { sensitivity in patients and rodents }\end{array}$ & 15,182 \\
\hline PPAR $\gamma$ & 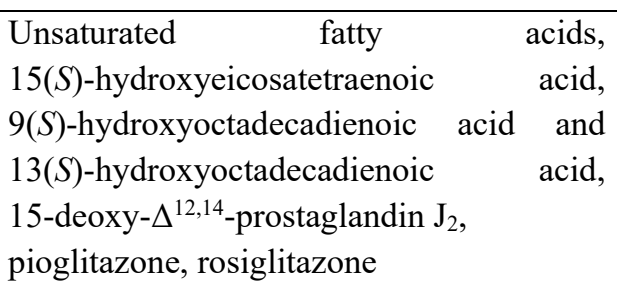 & $\begin{array}{l}\text { Improved glucose tolerance in } \\
\text { patients with type } 2 \text { diabetes } \\
\text { mellitus }\end{array}$ & $113,114,183$ \\
\hline $\begin{array}{l}\operatorname{PPAR} \alpha \text { and } \\
\operatorname{PPAR} \gamma\end{array}$ & Saroglitazar and tesaglitazar & $\begin{array}{l}\text { Improved glucose and lipid profile } \\
\text { in patients with dyslipidaemia }\end{array}$ & 16 \\
\hline $\begin{array}{l}\text { PPAR } \alpha \text { and } \\
\text { PPAR } \delta\end{array}$ & Elafibranor (GFT505) & $\begin{array}{l}\text { Decreased severity of non-alcoholic } \\
\text { steatohepatitis, improved lipid } \\
\text { profile in patients }\end{array}$ & 17 \\
\hline \multirow{2}{*}{$\begin{array}{l}\operatorname{PPAR} \alpha, \\
\operatorname{PPAR} \delta \quad \text { and } \\
\operatorname{PPAR} \gamma\end{array}$} & Lanifibranor & $\begin{array}{l}\text { Decreased severity of non-alcoholic } \\
\text { fatty liver disease in rodents }\end{array}$ & 18 \\
\hline & Chiglitazar & $\begin{array}{lclc}\text { Improved } & \text { lipid } & \text { profile } & \text { and } \\
\text { decreased } & \text { insulin } & \text { resistance } & \text { in } \\
\text { obese mice } & & & \end{array}$ & 19 \\
\hline
\end{tabular}

PPAR, peroxisome proliferator-activated receptor. 
Table 2 | PPAR-mediated control of cardiac function and risk factors for CVD

\begin{tabular}{|c|c|c|c|}
\hline Target & Risk factors & PPAR actions & Refs \\
\hline Liver & $\begin{array}{l}\text { Obesity, non-alcoholic fatty liver } \\
\text { disease, non-alcoholic steatohepatitis, } \\
\text { atherogenic plasma lipid profile (high } \\
\text { triglyceride, high LDL-cholesterol } \\
\text { and low HDL-cholesterol levels) }\end{array}$ & $\begin{array}{l}\text { PPAR } \alpha \text { expression decreases with non-alcoholic } \\
\text { steatohepatitis progression } \\
\text { PPAR } \alpha \text { increases FAO and ApoA-I, ApoA-II and } \\
\text { lipoprotein lipase levels (directly and indirectly by } \\
\text { decreasing ApoC-III and increasing ApoA-V levels) } \\
\text { PPAR } \delta \text { increases FAO and ApoA-II levels and } \\
\text { decreases ApoC-III levels }\end{array}$ & $12,13,28$ \\
\hline $\begin{array}{l}\text { White } \\
\text { adipose } \\
\text { tissue }\end{array}$ & $\begin{array}{l}\text { The expansion of visceral adipose } \\
\text { tissue in obesity and diabetes mellitus } \\
\text { increases the risk of CVD; the adipose } \\
\text { tissue secretome exerts pro- } \\
\text { inflammatory and pro-atherogenic } \\
\text { actions, which increases the risk of } \\
\text { CVD }\end{array}$ & $\begin{array}{l}\text { PPAR } \gamma \text { increases insulin sensitivity by a lipid-steal } \\
\text { action } \\
\text { PPAR } \gamma \text { and PPAR } \delta \text { decrease inflammation }\end{array}$ & $12,98,101$ \\
\hline $\begin{array}{l}\text { Brown } \\
\text { adipose } \\
\text { tissue }\end{array}$ & $\begin{array}{l}\text { High energy expenditure, which } \\
\text { decreases the risk of CVD }\end{array}$ & $\begin{array}{l}\text { PPAR } \gamma \text { increases brown adipocyte differentiation } \\
\text { PPAR } \alpha \text { and PPAR } \gamma \text { increase white adipose tissue } \\
\text { browning } \\
\text { PPAR } \alpha \text { and PPAR } \delta \text { increase FAO and energy } \\
\text { expenditure }\end{array}$ & $3,62,65$ \\
\hline Intestine & $\begin{array}{l}\text { Altered epithelial barrier function and } \\
\text { gut microbiota can increase the levels } \\
\text { of pro-inflammatory cytokines in the } \\
\text { plasma, thereby increasing the risk of } \\
\text { CVD and non-alcoholic fatty liver } \\
\text { disease }\end{array}$ & $\begin{array}{l}\text { PPAR } \alpha \text { increases FAO in intestinal epithelial cells } \\
\text { and HDL production and decreases chylomicron } \\
\text { secretion } \\
\text { PPAR } \gamma \text { protects gut microbiota and the epithelial } \\
\text { barrier } \\
\text { PPAR } \delta \text { decreases dyslipidaemia and increases } \\
\text { glucagon-like peptide } 1 \text { secretion }\end{array}$ & $\begin{array}{l}12,60,76,77,79 \\
81\end{array}$ \\
\hline $\begin{array}{l}\text { Skeletal } \\
\text { muscle }\end{array}$ & $\begin{array}{l}\text { Beneficial effects on glucose and lipid } \\
\text { metabolism and body weight control }\end{array}$ & $\begin{array}{l}\text { PPAR } \alpha \text { increases FAO } \\
\text { PPAR } \gamma \text { increases insulin sensitivity } \\
\text { PPAR } \delta \text { increases exercise endurance, FAO and the } \\
\text { glycolytic-to-oxidative muscle fibre switch, delays } \\
\text { carbohydrate depletion during exercise and } \\
\text { increases mitochondrial biogenesis }\end{array}$ & $12,83,87,88$ \\
\hline $\begin{array}{l}\text { Vascular } \\
\text { wall and } \\
\text { immune } \\
\text { system }\end{array}$ & $\begin{array}{l}\text { Atherogenic profile, atherosclerosis } \\
\text { and cardiovascular events }\end{array}$ & $\begin{array}{l}\text { PPAR } \alpha, \operatorname{PPAR} \gamma \text { and PPAR } \delta \text { increase vasomotricity } \\
\text { and decrease production of reactive oxygen species } \\
\text { PPAR } \alpha \text { and PPAR } \gamma \text { decrease the expression of } \\
\text { adhesion molecules, immune cell infiltration and } \\
\text { foam cell formation } \\
\text { PPAR } \gamma \text { and PPAR } \delta \text { decrease vascular smooth } \\
\text { muscle cell proliferation }\end{array}$ & $92,98,99,101$ \\
\hline Heart & $\begin{array}{l}\text { Altered cardiac metabolism in heart } \\
\text { failure }\end{array}$ & $\begin{array}{l}\text { PPAR } \alpha \text { and PPAR } \delta \text { increase FAO } \\
\text { PPAR } \gamma \text { increases lipid uptake and storage as lipid } \\
\text { droplets } \\
\text { PPAR } \delta \text { increases glycolysis }\end{array}$ & $140,141,145$ \\
\hline
\end{tabular}

Apo, apolipoprotein; CVD, cardiovascular disease; FAO, fatty acid oxidation; PPAR, peroxisome proliferator-activated receptor. 
Table 3 | Genetic mouse models to study PPAR functions

\begin{tabular}{|c|c|c|c|}
\hline Tissue & Model & Phenotype & Refs \\
\hline Liver & $\begin{array}{l}\text { Hepatocyte } \quad \text { PPAR } \alpha \\
\text { deficiency }\end{array}$ & $\begin{array}{l}\text { Increased liver steatosis and inflammation, } \\
\text { hyperlipidaemia, hypercholesterolemia and increased } \\
\text { extrahepatic FAO }\end{array}$ & $\begin{array}{l}30- \\
32,33\end{array}$ \\
\hline $\begin{array}{l}\text { White adipose } \\
\text { tissue }\end{array}$ & $\begin{array}{l}\text { Adipocyte } \\
\text { deficiency }\end{array}$ & Metabolic inflexibility of adipose tissue & 55 \\
\hline $\begin{array}{l}\text { Perivascular } \\
\text { adipose tissue }\end{array}$ & $\begin{array}{l}\text { Brown adipocyte PPAR } \gamma \\
\text { deficiency }\end{array}$ & Larger atherosclerotic lesions than in wild-type mice & 70 \\
\hline Intestine & $\begin{array}{ll}\begin{array}{l}\text { Enterocyte } \\
\text { deficiency }\end{array} & \text { PPAR } \delta \\
\end{array}$ & Increased dyslipidaemia and insulin resistance & 60 \\
\hline Endothelium & $\begin{array}{l}\text { Endothelial cell PPAR } \gamma \\
\text { deficiency }\end{array}$ & $\begin{array}{lll}\text { Accelerated age-induced vascular dysfunction, } \\
\text { inflammation and senescence }\end{array}$ & 93 \\
\hline \multirow[t]{2}{*}{ Skeletal muscle } & PPAR $\delta$ overexpression & 'Marathon runner-like' phenotype & 82,83 \\
\hline & PPAR $\alpha$ overexpression & $\begin{array}{l}\text { Increased FAO and protection against obesity but glucose } \\
\text { intolerance }\end{array}$ & 88 \\
\hline Whole body & PPAR $\alpha$ deficiency & $\begin{array}{l}\text { Switch from fatty acid to glucose and lactate metabolism } \\
\text { in the heart; disrupted mitochondrial function and lipid } \\
\text { accumulation in cardiomyocytes }\end{array}$ & 134,135 \\
\hline \multirow[t]{7}{*}{ Heart } & $\begin{array}{l}\text { Cardiomyocyte PPAR } \alpha \\
\text { deficiency }\end{array}$ & Not described & - \\
\hline & $\begin{array}{l}\text { Cardiomyocyte } \operatorname{PPAR} \delta \\
\text { deficiency }\end{array}$ & $\begin{array}{l}\text { Decreased fatty acid transport and FAO; lipid } \\
\text { accumulation in cardiomyocytes; cardiac hypertrophy } \\
\text { and dysfunction }\end{array}$ & 142 \\
\hline & $\begin{array}{l}\text { Cardiomyocyte } \operatorname{PPAR} \alpha \\
\text { overexpression }\end{array}$ & $\begin{array}{l}\text { Increased fatty acid uptake and FAO; cardiomyocyte lipid } \\
\text { accumulation; cardiomyopathy; mimics the diabetic heart } \\
\text { phenotype }\end{array}$ & 139,140 \\
\hline & $\begin{array}{l}\text { Cardiomyocyte inducible } \\
\text { PPAR } \alpha \text { overexpression }\end{array}$ & $\begin{array}{l}\text { Short-term PPAR } \alpha \text { activation early after transaortic } \\
\text { constriction procedure maintained cardiac fatty acid } \\
\text { oxidation }\end{array}$ & 169 \\
\hline & $\begin{array}{l}\text { Cardiomyocyte } \mathrm{PPAR} \gamma \\
\text { overexpression }\end{array}$ & $\begin{array}{l}\text { Increased lipid uptake, synthesis and storage; increased } \\
\text { glucose uptake; cardiac hypertrophy, dilatation and } \\
\text { dysfunction }\end{array}$ & 133 \\
\hline & $\begin{array}{l}\text { Cardiomyocyte } \operatorname{PPAR} \delta \\
\text { overexpression }\end{array}$ & $\begin{array}{l}\text { Increased FAO without increased expression of proteins } \\
\text { involved in fatty acid transport; increased expression of } \\
\text { proteins involved in glucose transport; increased } \\
\text { glycolysis; no lipid accumulation; no cardiac hypertrophy } \\
\text { or dysfunction in mice fed a high-fat diet }\end{array}$ & 140 \\
\hline & $\begin{array}{l}\text { Inducible cardiomyocyte } \\
\text { PPAR } \delta \text { overexpression }\end{array}$ & $\begin{array}{l}\text { Increased cardiac fatty acid and glucose metabolism, } \\
\text { mitogenesis, oxidative phosphorylation and scavenging } \\
\text { of reactive oxygen species }\end{array}$ & 141 \\
\hline
\end{tabular}

FAO, fatty acid oxidation; PPAR, peroxisome proliferator-activated receptor. 
Fig. 1 | Metabolic switches driven by the PPAR and HIF-mTOR pathways during heart

failure. The diameter of the pie charts is proportional to the absolute oxygen consumption and, therefore, the mechanical energy produced by the heart under each condition. The failing heart is characterized by low oxygen consumption capacity at rest and little metabolic reserve. Moreover, a return to a 'fetal-like' phenotype occurs, with an increased activity of hypoxiainducible factor (HIF) and mechanistic target of rapamycin (mTOR) instead of peroxisome proliferator-activated receptor- $\alpha(\operatorname{PPAR} \alpha)$ and PPAR $\delta$ dominance, leading to a metabolic switch to the use of carbohydrates as preferential substrates. This switch further favours anabolism and cardiomyocyte hypertrophy.

Fig. 2 | PPAR regulation of cardiomyocyte metabolism. The 'omnivorous' heart catabolizes all types of energy sources, including fatty acids (FAs), glucose, ketone bodies and branchedchain amino acids (BCAAs) to deliver constant mechanical work. Peroxisome proliferatoractivated receptors (PPARs) are major regulators of cardiomyocyte metabolism that regulate proteins and enzymes involved in energy substrate degradation pathways. In brief, PPAR $\alpha$ regulates FA transport and mitochondrial $\beta$-oxidation ( $\beta$-Ox) in cardiomyocytes. PPAR $\alpha$ also stimulates triglyceride (TG) synthesis and lipid droplet (LD) formation in an environment with an excess of FAs. PPAR $\delta$ increases fatty acid oxidation and glycolysis and promotes mitochondrial biogenesis. PPAR $\gamma$ regulates LD formation and TG lipolysis, increasing neutral lipid accumulation in LDs, thereby limiting the accumulation of cardiac cytotoxic lipids. Upstream pathways, including hypoxia-inducible factor (HIF) and mammalian target of rapamycin (mTOR), participate actively in the regulation of cardiac metabolism by modulating PPAR expression. Direct effects are illustrated in full lines and indirect effects in dashed lines. ATGL, adipose triacylglycerol lipase; CPT, carnitine $O$-palmitoyltransferase; DAG, diacylglycerol; DGAT, diacylglycerol acyltransferase; FAT, fatty acid translocase; FATP1, 
fatty acid transport protein 1; G6P, glucose-6-phosphate; GLUT, glucose transporter; GPAT, glycerol-3-phosphate acyltransferase; HK, hexokinase; HSL, hormone-sensitive lipase; LAT, L-type amino acid transporter; LCAD, long-chain specific acyl-CoA dehydrogenase; LDH, lactate dehydrogenase; MCAD, medium-chain specific acyl-CoA dehydrogenase; MCT, monocarboxylate transporter; MPC, mitochondrial pyruvate carrier; $\mathrm{PDH}$, pyruvate dehydrogenase; PDK, pyruvate dehydrogenase kinase; PFK, phosphofructokinase; TCA, tricarboxylic acid; RAAS, renin-angiotensin-aldosterone system; RXR, retinoid X receptor. 


\section{Box 1 | Metabolic activity of the heart throughout development \\ The 'omnivorous heart'}

The heart needs to deliver constant mechanical work while facing a life-long changing environment. The diameter of the pie chart (see the figure) is quantitatively proportional to the absolute oxygen consumption and, therefore, the mechanical energy produced by the heart. The nutritional energy supply of the heart changes during different periods of life, from fetal to adult, and during the day (fasting versus post-prandial versus exercise periods). As illustrated, at maximal exercise, a fourfold to fivefold increase in energy metabolism fluxes matches the increase in cardiac stroke work to maintain the high-energy phosphate content at a constant level.

To cope with this high metabolic challenge, the heart is equipped with the necessary enzymatic machinery that, theoretically, enables the heart to catabolize all types of energy nutrients, including fatty acids, carbohydrates (such as glucose and lactate), ketone bodies and branched-chain amino acids ${ }^{184}$. Therefore, the heart is 'omnivorous', and its energy metabolism is flexible to utilize the nutrients delivered by the coronary circulation, such as glucose in the post-prandial period, lactate during exercise, and fatty acids and ketone bodies during overnight fasting ${ }^{155,185,186}$.

\section{PPARs in the fetal-to-adult maturation of cardiac metabolism}

The fetal heart is exposed to low oxygen and fatty acid levels, whereas the levels of blood lactate are high and glucose concentrations are similar to those in adults ${ }^{187}$ (see the figure, fetus section). This fetal cardiomyocyte metabolic phenotype has high quantities of glycolysis intermediates, such as glucose-6-phosphate, necessary for nucleotide, amino-acid and lipid biosynthesis ${ }^{126}$, and necessary to support the growth and anabolism required for cardiomyocyte

multiplication $^{127}$. This metabolism is associated with low levels of peroxisome proliferatoractivated receptor- $\alpha(\operatorname{PPAR} \alpha)$ and PPAR $\delta$ activity and high levels of hypoxia-inducible factor 
(HIF) and mechanistic target of rapamycin (mTOR) activity. Within the first days of life, the metabolic phenotype of cardiomyocytes switches in response to two major environmental changes: the increase in arterial oxygen partial pressure (from approximately $35 \mathrm{mmHg}$ to $100 \mathrm{mmHg}$ in humans) and the delivery of fatty acids from breast milk. This environment induces a switch in cardiac metabolism to fatty acid oxidation to produce energy as a result of low activity of HIF and high activity of PPAR $\alpha$ and PPAR $\delta$-PPAR $\gamma$-coactivator $1 \alpha^{125}$. This state is maintained throughout adult life.

\section{ToC}

Novel PPAR agonists are providing new opportunities in the management of metabolic and cardiovascular diseases. In this Review, Staels and colleagues discuss the physiological regulation and actions of the PPAR family and their modulation of the atherogenic lipid profile, atherosclerosis and cardiac remodelling. 


\section{FETUS}
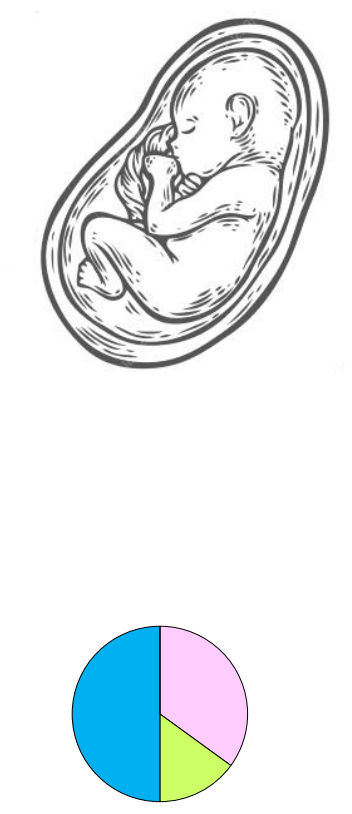

NEWBORN

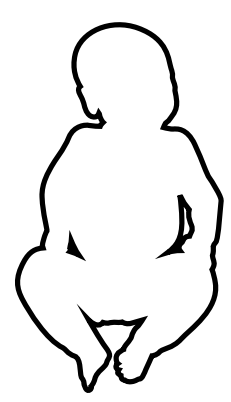

个Fatty acids

个Oxygen

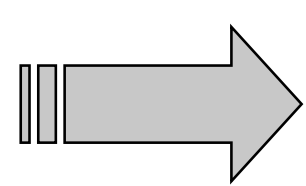

\section{ADULT HEART}
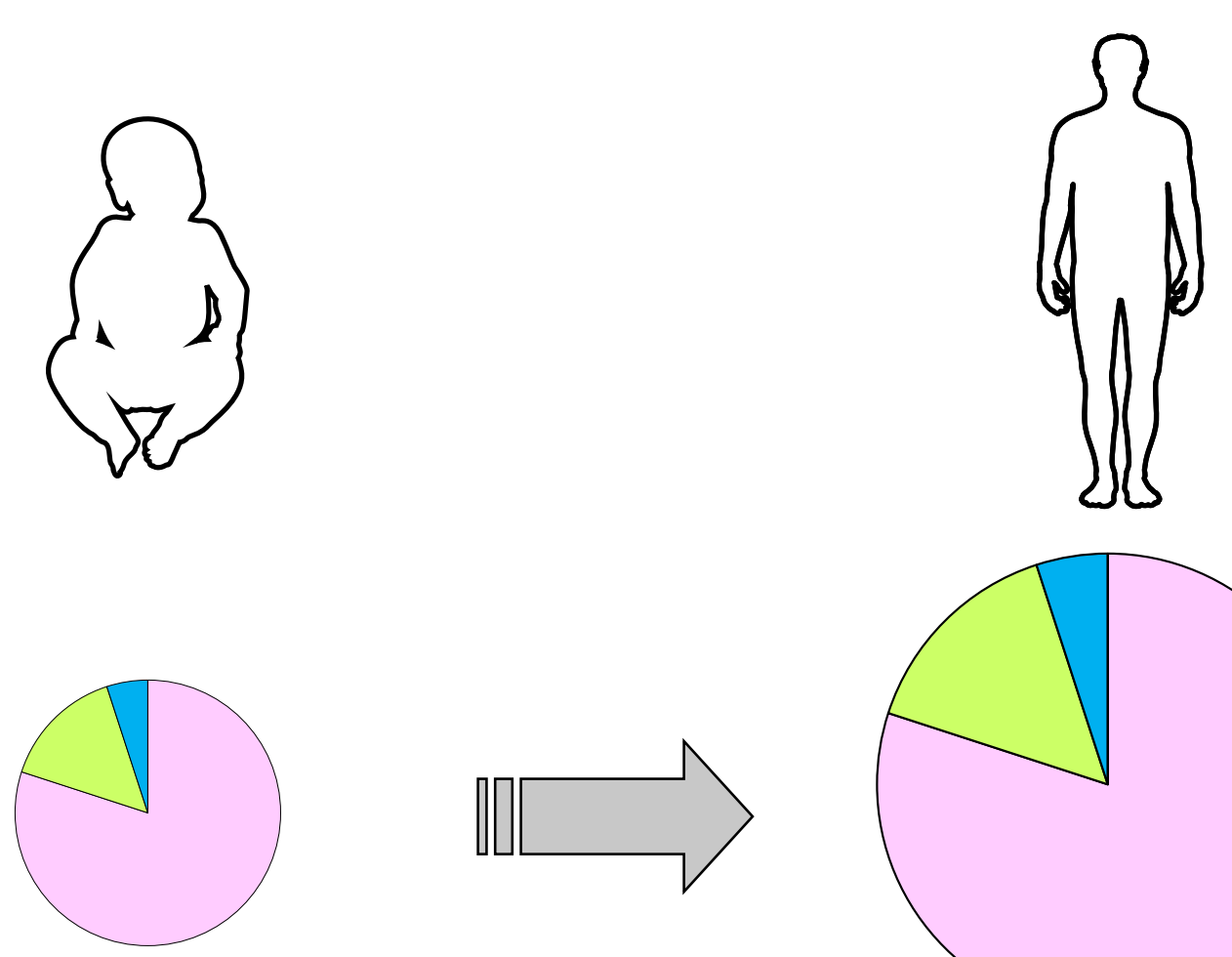

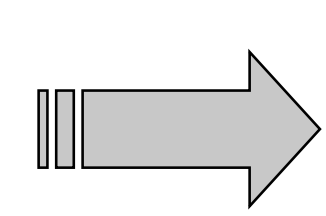

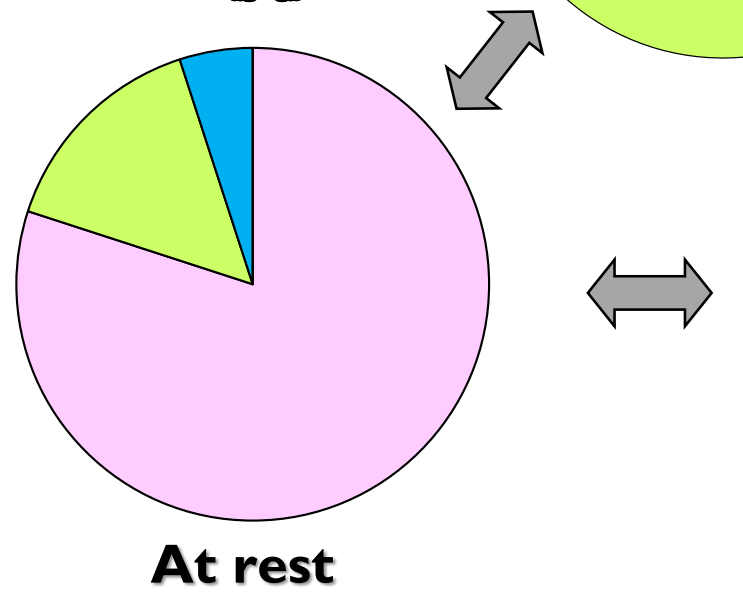

At rest

\section{PPARa/PPARס}

\section{HIF/mTOR (PPARy)}

Into Box1: Metabolic switches driven by the PPAR and HIF/mTOR pathways during physiological cardiac development

The fetal heart mainly uses carbohydrates as energy substrates, associated with low PPAR $\alpha / P P A R \delta$ activity and highly active HIF and mTOR regulatory pathways. At birth, due to the change to an environment enriched in oxygen and fatty acids from milk, a metabolic switch occurs : fatty acids become the preferential energy substrates and the PPAR $\alpha$ and PPAR $\delta$ regulatory pathways are activated to degrade the fatty acids. This is maintained in adult life. The diameter of the pie charts is quantitatively proportional to the absolute oxygen consumption, and thus the mechanical energy produced by the heart, under that given condition. The energy produced by the heart increases throughout life and is enhanced during exercise. 


\section{HEALTHY HEART}

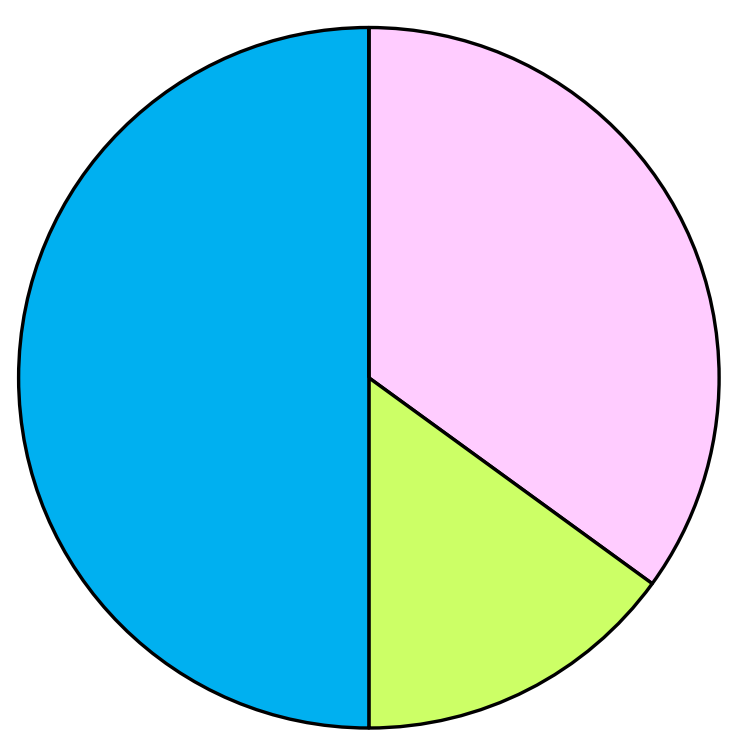

Exercise

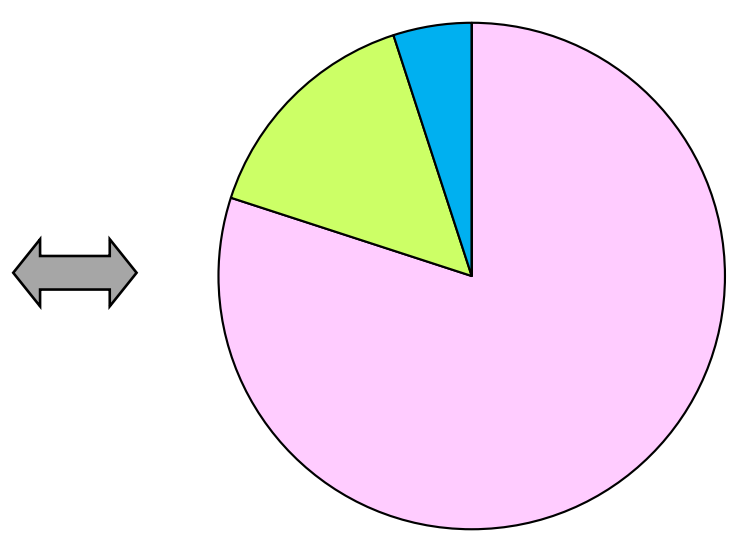

At rest

\section{FAILING HEART}

Energy starvation with lack of metabolic reserve ; anabolism

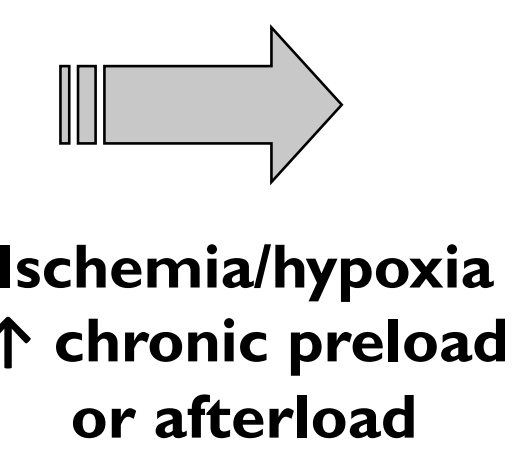

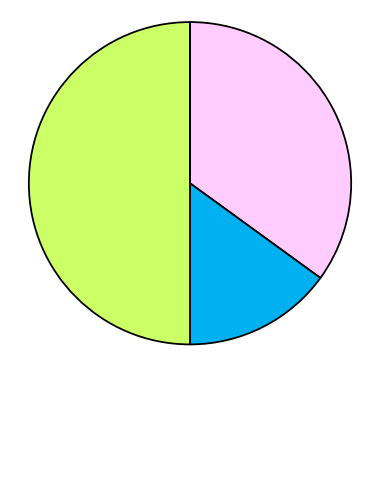

At rest

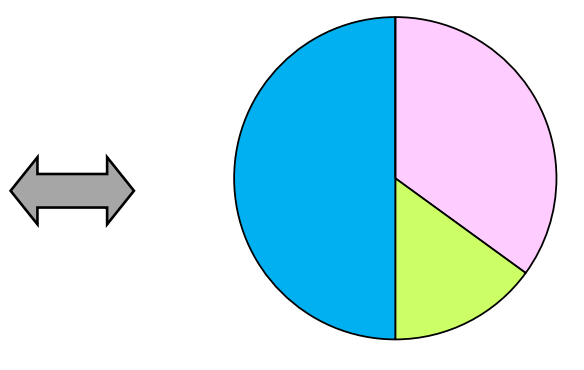

Exercise

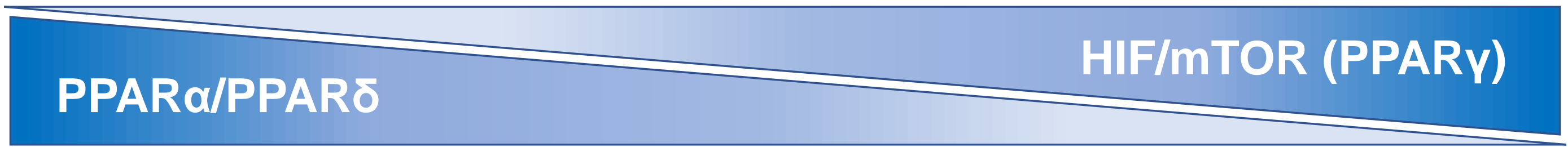

Fatty acids

O Glucose

O Lactate

Fig 1: Metabolic switches driven by the PPAR and HIF/mTOR pathways during heart failure

The diameter of the pie charts is quantitatively proportional to the absolute oxygen consumption, and thus the mechanical energy produced by the heart, under that given condition. The failing heart is characterized by low oxygen consumption capacity at rest and little metabolic reserve.

Moreover, a return to a "fetal-like" phenotype occurs, with an increased activity of HIF and mTOR instead of PPAR $\alpha$ and PPAR $\delta$ dominance, leading to a metabolic switch with carbohydrates as preferential substrates. This switch further favors anabolism and cardiomyocyte hypertrophy. 


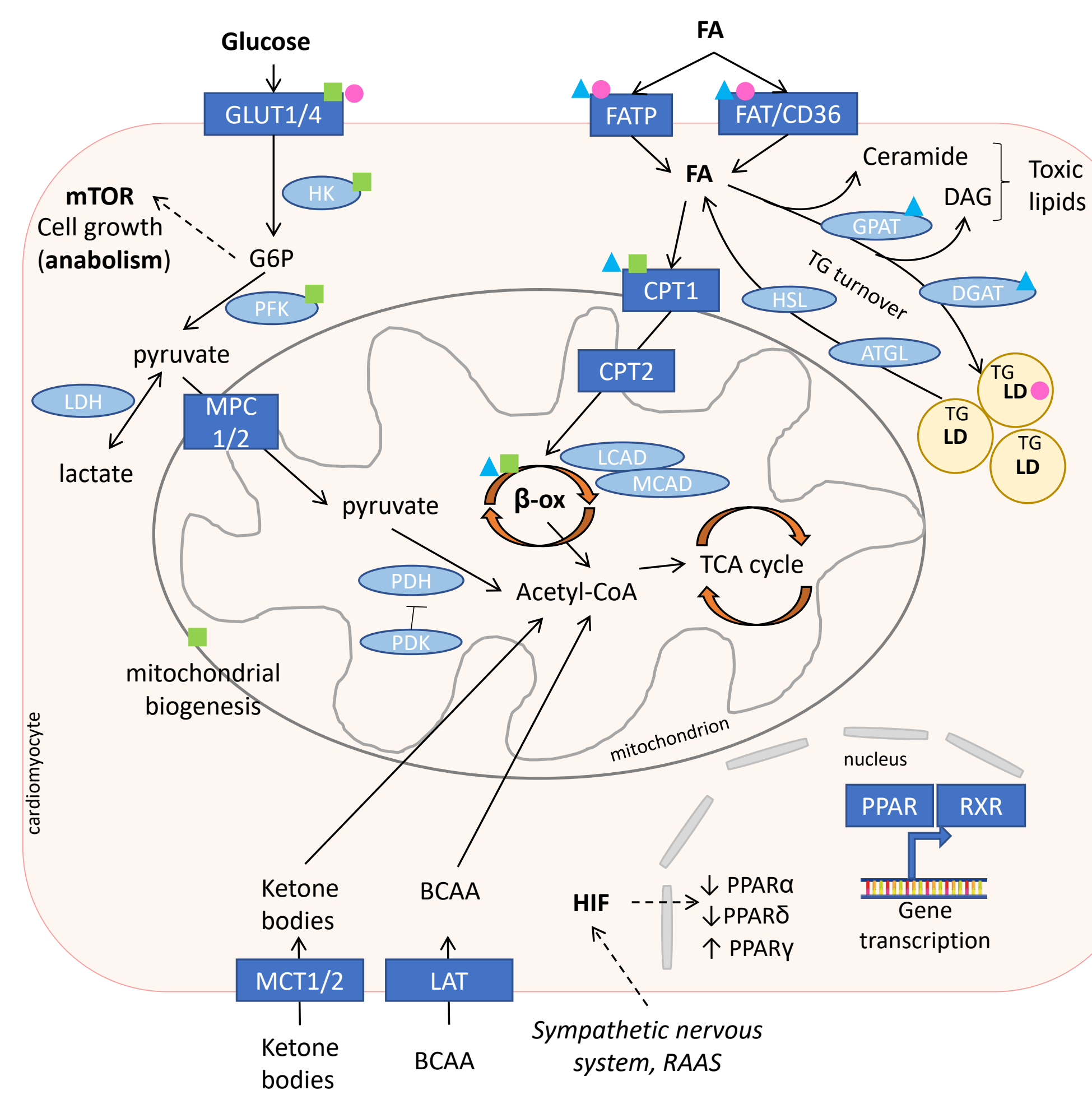

Fig 2: PPAR regulation of cardiomyocyte metabolism

The "omnivorous" heart catabolizes all types of energy sources: fatty acids (FA), glucose, ketone bodies and branched-chain amino-acids to deliver a constant mechanical work. PPARs are major regulators of cardiomyocyte metabolism regulating proteins and enzymes involved in energy substrate degradation pathways. (Regulated by: $\triangle$ PPAR $\square$ PPAR $O$ PPARY)

PPAR: peroxisome proliferator-activated receptor, GLUT: glucose transporter, HK: hexokinase, PFK: phosphofructokinase, LDH: lactate dehydrogenase, MPC: mitochondrial pyruvate carrier, PDH: pyruvate dehydrogenase, PDK: pyruvate dehydrogenase kinase, ATGL: adipose triacylglycerol lipase, HSL, hormone sensitive lipase, MGL: monoacylglycerol lipase, TG: triglycerides, FATP: fatty acid transport protein, FAT/CD36: fatty acid translocase/cluster of differentiation 36, GPAT: glycerol-3-phosphate acyltransferase, DGAT: diacylglycerol acyltransferase, CPT: carnitine-palmitoyl transferase, $\beta$-ox: beta-oxydation, LCAD: longchain acyl-CoA dehydrogenase, MCAD: medium-chain acyl-CoA dehydrogenase, TCA: tricarboxylic acid cycle, mTOR: mammalian target of rapamycin, HIF: hypoxia inducible factor, MCT: monocarboxylate transporter, BCAA: branched-chain amino acids, LAT: L-type amino acid transporter, RXR: retinoid $X$ receptor, RAAS, renin angiotensin aldosterone system, G6P, glucose-6-phosphate, LD: Lipid droplet. Direct effects are schematized in full lines and indirect effects in stippled line. 